\title{
Responses of resistant and susceptible hybrid clones of Eucalyptus urophylla $\times$ Eucalyptus grandis to infection by Ceratocystis fimbriata
}

\author{
André C. Silva ${ }^{1,2} \cdot$ Blanca M. L. Betancourth ${ }^{3} \cdot$ Diego C. Ferreira $^{4} \cdot$ Tamiris L. Elerati $^{5} \cdot$ Fabrício Á. Rodrigues $^{1}$. \\ Acelino C. Alfenas ${ }^{1}$
}

Received: 22 January 2019 / Accepted: 19 February 2020 / Published online: 7 May 2020

(C) INRAE and Springer-Verlag France SAS, part of Springer Nature 2020

\begin{abstract}
- Key message A histopathological study using one resistant and one susceptible clone of Eucalyptus urophylla $\times$ Eucalyptus grandis hybrid showed that the colonization of Ceratocystis fimbriata was limited by rapid and intense host defense responses such as closure of the vessel pits; formation of tyloses and gels; accumulation of amorphous material, starch, phenolic compounds, and calcium oxalate; and tissue lignification. The defense mechanisms of the resistant clone were not lethal to the pathogen because the fungus was reisolated from the diseased tissue.

- Context The use of resistant genotypes of eucalypt is widely used to control Ceratocystis wilt caused by Ceratocystis fimbriata. However, little is known regarding the fungal infection process and the host defense responses.

- Aims Thus, the objectives of this study were to compare the histopathological responses of one resistant and one susceptible clone of Eucalyptus urophylla $\times$ Eucalyptus grandis to artificial inoculation with $C$. fimbriata and to identify possible host defense responses against fungal infection.

- Methods Fungal colonization was analyzed by light and scanning electron microscopy. The host defense responses to artificial fungal inoculation were evaluated through histochemical analysis and determining of the lignin concentration and lesion lengths, whereas the pathogen viability was confirmed by reisolations.

- Results Both tested clones showed similar responses against fungal infection but presented defense responses with different speeds and intensities. Fungal colonization was not restricted in the tissue of plants from the susceptible clone, whereas in the resistant clone, fungal colonization was limited to the xylem vessels and parenchyma around the vessels due to closure of the vessel pits; intense formation of tyloses and gels; accumulation of amorphous material, starch, phenolic compounds, and calcium oxalate; and tissue lignification. However, the fungus was reisolated from the inoculated tissues of both clones.
\end{abstract}

\section{Handling Editor: Cécile Robin}

Contribution of the co-authors André C. Silva: designing the experiment, conducting the experiment, running and analyzing the data, and writing the manuscript. Blanca M. L. Betancourth: conducting the experiment and writing the manuscript. Diego C. Ferreira: conducting the experiment and analyzing the data. Tamiris L. Elerati: conducting the experiment. Fabrício Á. Rodrigues: writing the manuscript. Acelino C. Alfenas: coordinating the research project, designing and supervising the experiment, and writing the manuscript.

Acelino C. Alfenas

aalfenas@ufv.br

André C. Silva

andrec_agro@yahoo.com.br

Blanca M. L. Betancourth

blancamlb06@gmail.com

Diego C. Ferreira

diegoferreir1@gmail.com
Tamiris L. Elerati
tamiris.elerati@gmail.com

Fabrício Á. Rodrigues

fabricio@ufv.br

Extended author information available on the last page of the article 
- Conclusion The resistance of eucalypt cuttings was found to be based on the rapid and intense defense responses shaped by biochemical and structural mechanisms that contained fungal colonization in the xylem vessels and parenchyma tissues.

Keywords Ceratocystis wilt $\cdot$ Phenylpropanoid pathway $\cdot$ Histochemical analysis $\cdot$ Histopathology $\cdot$ Vascular pathogen

\section{Introduction}

The expansion of eucalypt plantations to new forest frontiers in the south, north, and northeast of Brazil as well as to several parts of the world has led to the occurrence of several biotic diseases, which have limited the planting of certain genetic materials (Alfenas et al. 2009). Among them, Ceratocystis wilt, which is caused by Ceratocystis fimbriata Ellis \& Halsted, is currently one of the most important diseases in eucalypt. This pathogen has a wide geographic distribution and a broad host range and results in significant yield losses (Alfenas et al. 2009; Fernandes et al. 2014; Mafia et al. 2013). This disease can reduce the volumetric growth of trees in the field by up to $87 \%$, the cellulose yield by approximately $14 \%$, and the value of wood for sawing (Mafia et al. 2013). Trees with an advanced stage of the disease might die.

Despite the losses caused by this disease, little is known regarding the infection process of $C$. fimbriata in eucalypt plants and the mechanisms of innate plant resistance, which are the first to be activated during the host-pathogen interaction. Up to now, it is known that $C$. fimbriata induces longitudinal and radial darkening of wood and infects the xylem and phloem vessels and phelloderm causing tree wilt (Ferreira et al. 2006). Conidia, aleuroconidia, and ascospores of Ceratocystis isolates from different hosts (e.g., eucalypts, cocoa, mango, teak, and atemoya) are capable of germinating, penetrating, and developing in the vessel elements of eucalypt plants within $6 \mathrm{~h}$ (Firmino et al. 2015). The resistance of eucalypt plants to $C$. fimbriata is related to enzymatic activity (e.g., polyphenol oxidase and peroxidase activities) and accumulation of sugar, antimicrobial compounds (e.g., flavone, hesperetin, loganin, and nicotinamide), and phenolic compounds (Silva et al. 2018; Pimenta et al. 2017). Firmino et al. (2018) concluded that the resistance of eucalypt to Ceratocystis wilt might be related to the capacity of plants to accumulate lignin in cells.

There are currently no chemical molecules available for disease control. Deployment of resistant material is the only available and efficient method for controlling Ceratocystis wilt in eucalypt (Silva et al. 2018; Alfenas et al. 2009; Zauza et al. 2004). Several eucalypt clones resistant to Ceratocystis wilt have been identified (Firmino et al. 2013; Tumura et al. 2012; Zauza et al. 2004), but the mechanisms confering resistance to fungal infection have not yet been elucidated in detail. The infectious process of $C$. fimbriata and the host responses can be investigated through histopathological and histochemical analyses of infected plants of eucalypt clones with different levels of resistance, and this information can be used for genetic improvements aiming to obtain clones with great resistance to Ceratocystis wilt.

Inter- and intraspecific crossing is usually done to obtain resistant and highly productive genetic materials (Alfenas et al. 2009). Identification of structural and/or biochemical mechanisms that confer resistance might be important to obtain new productive and long-term resistant clones originated from breeding programs.

To test the hypothesis that the responses of eucalypt plants to Ceratocystis wilt include structural and/or local or systemic biochemical defense mechanisms, we compared the histopathological responses in one resistant clone and one susceptible clone of Eucalyptus urophylla $\times$ Eucalyptus grandis to artificial inoculation with $C$. fimbriata. An improved understanding of the fungal infection process might assist with the identification of resistance mechanisms to Ceratocystis wilt.

\section{Material and methods}

\subsection{Plant materials and growth}

Clones of two Eucalyptus urophylla $\times$ E. grandis hybrids with different levels of resistance to Ceratocystis wilt, namely, clones CLR212 (resistant) and CLR240 (susceptible), were used in this study. The resistance of these two clones to Ceratocystis wilt was previously evaluated by artificial fungal inoculation (Oliveira et al. 2015). Cuttings of the two clones were transplanted into plastic pots containing $2 \mathrm{~L}$ of Carolina Soil substrate (Carolina Soil do Brasil®, Santa Cruz do Sul, RS, Brazil) enriched with superphosphate $\left(6 \mathrm{~kg} \mathrm{~m}^{-3}\right)$ and Osmocote ${ }^{\circledR}$ (NPK 19:06:10; $1.5 \mathrm{~kg} \mathrm{~m}^{-3}$ ). Prior to inoculation, the cuttings were maintained in a greenhouse (temperature ranging from 20 to $30{ }^{\circ} \mathrm{C}$ ) during 45 to 60 days until their stem reached approximately $8 \mathrm{~mm}$ in diameter.

\subsection{Fungal inoculum}

The isolate SBS-1 of $C$. fimbriata used in this study was obtained from the mycological collection of the "Laboratorio de Patologia Florestal/Bioagro da Universidade Federal de Viçosa (UFV)" and was previously identified based on its morphological and molecular characteristics. The fungus was cultivated in Petri dishes containing MEYA culture medium (2\% malt extract, $0.2 \%$ yeast extract, and $2 \%$ agar) for 15 days in an incubator at $28 \pm 1{ }^{\circ} \mathrm{C}$ with a 12 -h photoperiod at 
$40 \mu \mathrm{mol} \mathrm{s}{ }^{-1} \mathrm{~m}^{-2}$. For harvesting of spores, sterile water containing $1 \%$ Tween 20 was added to the plates and the surface of the colony was scraped with a sterile Drigalski loop. The spore suspension was filtered through a double layer of gauze and adjusted to a concentration of $2.5 \times 10^{6}$ spores $\mathrm{mL}^{-1}$.

\subsection{Inoculation protocols and incubation conditions}

A perforation with a depth of $4 \mathrm{~mm}$ was made in the cuttings $5 \mathrm{~cm}$ above the soil line using a sterile hypodermic needle ( $2 \mathrm{~mm}$ in diameter). The cuttings were then inoculated with $200 \mu \mathrm{L}$ of the inoculum suspension. Wounded cuttings injected with $1 \%$ Tween 20 aqueous solution were used as a control. The inoculation point was covered with PVC film and the cuttings were maintained in a greenhouse (average temperature and relative humidity of $24.5^{\circ} \mathrm{C}$ and $81.7 \%$, respectively) during the experiments.

\subsection{Symptoms evaluation}

Due to a significant isolate $\times$ clone interaction (Oliveira et al. 2015), the objectives of this trial were to confirm the resistance and susceptibility of the clones CLR212 and CRL240 to the isolate SBS-1 of C. fimbriata and to determine the potential of host biochemical defense mechanisms of the resistant clone to be lethal to the fungus. For this, the length of the lesion on the inner tissues of the stem was evaluated (above and below the point of inoculation or wounded) at 60 days after inoculation (dai). During the disease evaluation, stem fragments at the inoculation site were removed, and the fungus was reisolated using the carrot bait method (Moller and DeVay 1968) to verify its viability in the inoculated stem tissue. The experiment was performed using a completely randomized design with 15 replications per treatment (one cutting per replication) and repeated once. The data were subjected to analysis of variance and treatments means were compared by Duncan's tests at a probability of 5\%. The normality and homogeneity were evaluated using the residues in which no deviations were found based on the presuppositions involved in the analysis. The statistical analyses were performed using the R (R Development Core Team) software.

\subsection{Lignin concentration}

To evaluate the lignin content of both clones in response to infection, inoculated and wounded cuttings were used. At 6 dai, samples were collected from the stem (approximately $7 \mathrm{~cm}$ in length; $2 \mathrm{~cm}$ below and $5 \mathrm{~cm}$ above the inoculation or wounded point) placed in a paper bag, and dried in a forced air oven at $65^{\circ} \mathrm{C}$ until reaching constant weight. The acid-soluble lignin concentration was determined according to the Technical Association of the Pulp and Paper Industry's protocol (Tappi; Useful Method (UM) 250). The concentration of acid-insoluble lignin (Klason lignin) was determined using the standard procedure of the Technical Association of the Pulp and Paper Industry (Tappi; T222 om-98) with some modifications. The total lignin concentration was also determined. The experiment was carried out in a randomized block design with four replications per treatment (one cutting per replication). The data were subjected to analysis of variance and treatment means were compared by Duncan's tests at a probability of $5 \%$ as previously described.

\subsection{Histological observations}

To examine the initial processes of $C$. fimbriata colonization in the stem tissues of both clones and the response of cuttings to fungal infection, scanning electron microscopy (SEM) was used. For this experiment, the wound size and depth (approximately $2 \mathrm{~cm}$ in length, $8 \mathrm{~mm}$ in width, and $2 \mathrm{~mm}$ in depth) and the spore concentration $(0.5 \mathrm{~mL}$ at the concentration of $1.5 \times 10^{-5}$ spores $\mathrm{mL}^{-1}$ with $1 \%$ Tween 20 ) were different from the previously described to facilitate the visualization of the initial colonization of the fungus in the stem tissue. After inoculation, the cuttings were maintained in a growth chamber (temperature of $28 \pm 3{ }^{\circ} \mathrm{C}$ ) during the experiment. In addition, for the first $12 \mathrm{~h}$, the cuttings remained in the horizontal position to avoid the displacement of the inoculum deposited in the wound. Stem fragments $(0.5 \times 0.5 \mathrm{~cm})$ were collected 12, 24, 36, 48, and $60 \mathrm{~h}$ after inoculation (hai) and prepared for SEM using the protocols described by Silva et al. (2017). The experiment was performed using a completely randomized design with five replications per treatment (one cutting per replication) and repeated once.

Light microscopy and histochemical tests were also performed to evaluate fungal colonization and structural and biochemical reactions in the tissues of plants of both clones. The clones were inoculated using a hypodermic needle as previously described. Wounded cuttings injected with $1 \%$ Tween 20 aqueous solution and nonwounded cuttings served as controls. Stem tissue samples were collected at 1, 2, 4, 6, 8, 16, and 32 dai; fixed in a solution composed of formaldehyde, acetic acid, and 70\% alcohol (at a ratio of 5:5:90 v/v) (Johansen 1940); and stored in 70\% ethyl alcohol solution. The samples were dehydrated through an ethyl alcohol series $(80,90$, and $95 \%)$ and embedded in hydroxyethyl methacrylate (Historesin $\AA$, Leica) according to the manufacturer's instructions. The samples were sectioned into transverse and longitudinal thick sections (approximately $5 \mu \mathrm{m}$ ) using an automatic feed rotary microtome (RM 2155; Leica). The sections were stained with toluidine blue ( $\mathrm{pH} 4.0$ ) for $10 \mathrm{~min}$ and mounted with synthetic resin (Permount-Fisher) and with ferric chloride for the identification of phenolic compounds and lugol ( $1 \%$ iodine $+2 \%$ potassium iodide) for starch (Johansen 1940). Samples without any reagent or dye were mounted in water and used as controls for the comparison of the reaction 
Table 1 Mean length of the lesions in the CLR212 (resistant) and CLR240 (susceptible) eucalypts clones at 60 days after inoculation (dai) with Ceratocystis fimbriata and insoluble, soluble, and total lignin concentrations 6 dai. Uninoculated plants were used as controls

\begin{tabular}{lllll}
\hline Treatments & Lesion length $(\mathrm{cm})^{\mathrm{a}}$ & \multicolumn{2}{l}{ Lignin concentrations $(\%)$} \\
\cline { 3 - 5 } & & Insoluble $^{\mathrm{b}}$ & Soluble $^{\mathrm{b}}$ & Total $^{\mathrm{b}}$ \\
\hline Inoculated CLR212 & $5.3 \pm 0.24 \mathrm{~b}$ & $25.7 \pm 0.42 \mathrm{a}$ & $5.5 \pm 0.25 \mathrm{a}$ & $31.7 \pm 0.75 \mathrm{a}$ \\
Uninoculated CLR212 & $0.8 \pm 0.10 \mathrm{c}$ & $21.0 \pm 0.45 \mathrm{c}$ & $4.4 \pm 0.13 \mathrm{~b}$ & $25.4 \pm 0.52 \mathrm{c}$ \\
Inoculated CLR240 & $62.7 \pm 2.77 \mathrm{a}$ & $24.2 \pm 0.14 \mathrm{ab}$ & $4.7 \pm 0.06 \mathrm{~b}$ & $29.6 \pm 0.65 \mathrm{~b}$ \\
Uninoculated CLR240 & $0.9 \pm 0.09 \mathrm{c}$ & $23.9 \pm 0.17 \mathrm{~b}$ & $3.6 \pm 0.19 \mathrm{c}$ & $28.1 \pm 0.28 \mathrm{~b}$ \\
\hline
\end{tabular}

Averages followed by the same lowercase letter in a column are not different, as demonstrated by Duncan's test based on a probability of 5\%

${ }^{a}$ Mean values \pm standard errors obtained from 15 replicates

${ }^{\mathrm{b}}$ Mean values \pm standard errors obtained from four replicates

patterns. Images were captured and analyzed using an Olympus BX53 light microscope equipped with a Q-Color $5^{\mathrm{TM}}$ camera (Olympus Inc., USA) and an image analysis system (Image-Pro Plus Version 7.0 program). Furthermore, a graphical representation of the fungal colonization and host defense reactions observed in the histological sections was represented as a heatmap using Microsoft Excel (Microsoft Corporation, Seattle). The experiment was performed using a completely randomized design with three replications per treatment (one cutting per replication) and repeated once.
Fig. 1 Color map representing the intensity of the colonization in stem tissue of the CLR212 (resistant) and CLR240 (susceptible) clones of Eucalyptus urophylla $\times$ E. grandis by Ceratocystis fimbriata and host defense reactions determined by histochemical analysis. Blue or red regions indicate whether the intensity of fungal colonization and the host reaction were low or high, respectively, based on light and SEM microscopy images.

White color represents nonobserved reactions. Abbreviations: RI (resistant clone, inoculated), RW (resistant clone, wounded and noninoculated), RUW (resistant clone, unwounded), SI (susceptible clone, inoculated), SW (susceptible clone, wounded and noninoculated), and SUW (susceptible clone, unwounded) at $12,24,36,48$, and $60 \mathrm{~h}$ after inoculation as well as at $4,6,8$, 16 , and 32 days after inoculation

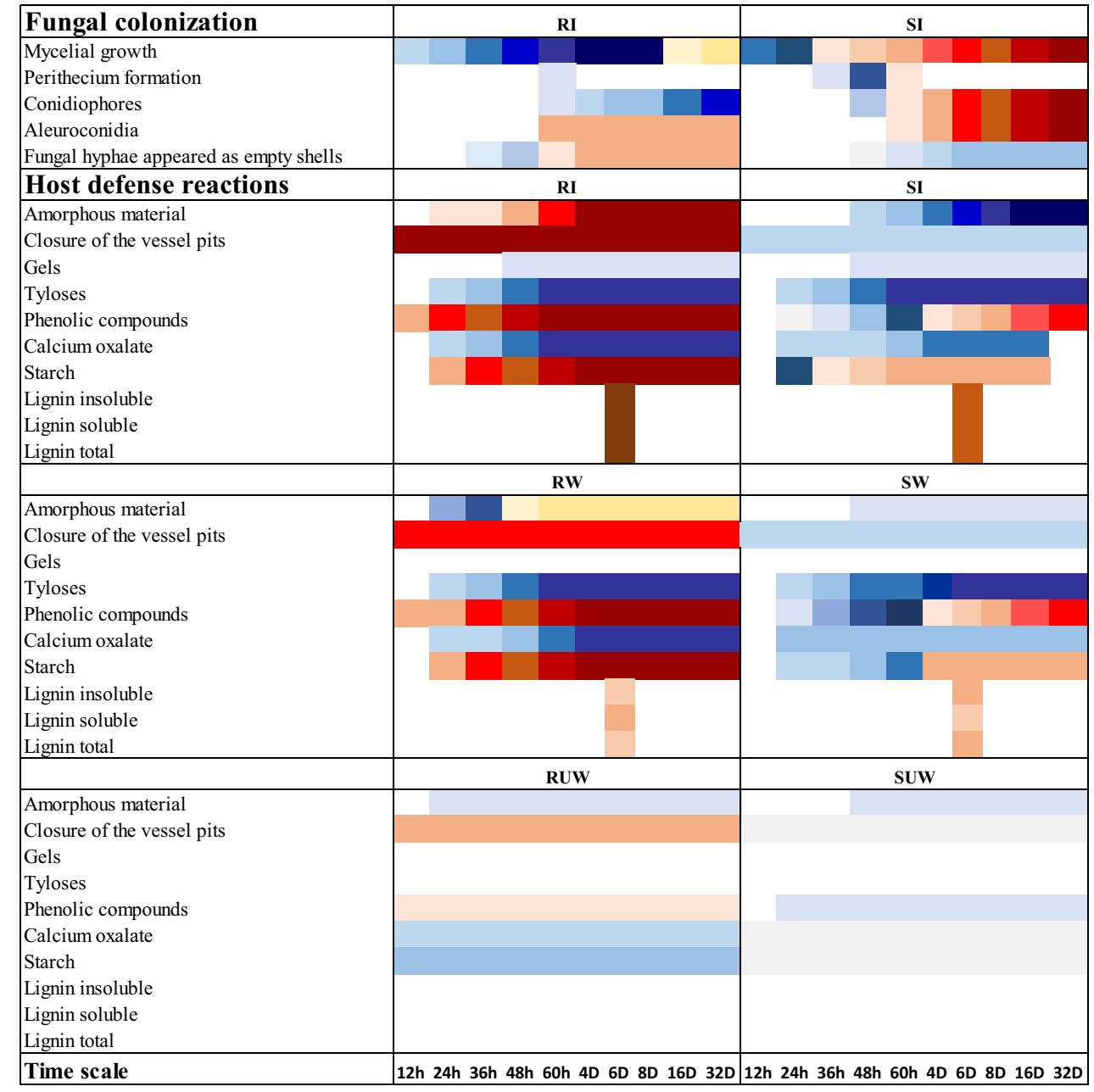


Fig. 2 Scanning electron

micrographs of stem tissues of plants of the CLR212 (resistant) (a, $\mathbf{c}, \mathbf{e}, \mathbf{g}$, and i) and CLR240 (susceptible) (b, d, f, h, and j) Eucalyptus urophylla $\times$ E. grandis clones colonized by Ceratocystis fimbriata. The micrographs were obtained 36 (ad, i, and j), 48 (e and f), and 60 (g and $\mathbf{h}) \mathrm{h}$ after inoculation. Arrows show mycelial growth $(\mathbf{a}-\mathbf{c}$ and $\mathbf{i})$, the formation of perithecia (d), fungal hyphae that appeared as empty shells (e and i), the formation of conidiophores (f), abundant aleuroconidia (g), the formation of perithecia in the resistant clone (g), and fully formed perithecia, conidiophores, conidia, and aleuroconidia in the susceptible clone (h). pe = perithecia, $\mathrm{cd}=$ conidiophores, and $\mathrm{al}=$ aleuroconidia. Scale bars $=10(\mathbf{d}, \mathbf{e}, \mathbf{i}$, and $\mathbf{j}), 20$ (f and $\mathbf{h})$, and $100 \mu \mathrm{m}(\mathbf{a}-\mathbf{c}$ and $\mathbf{g})$
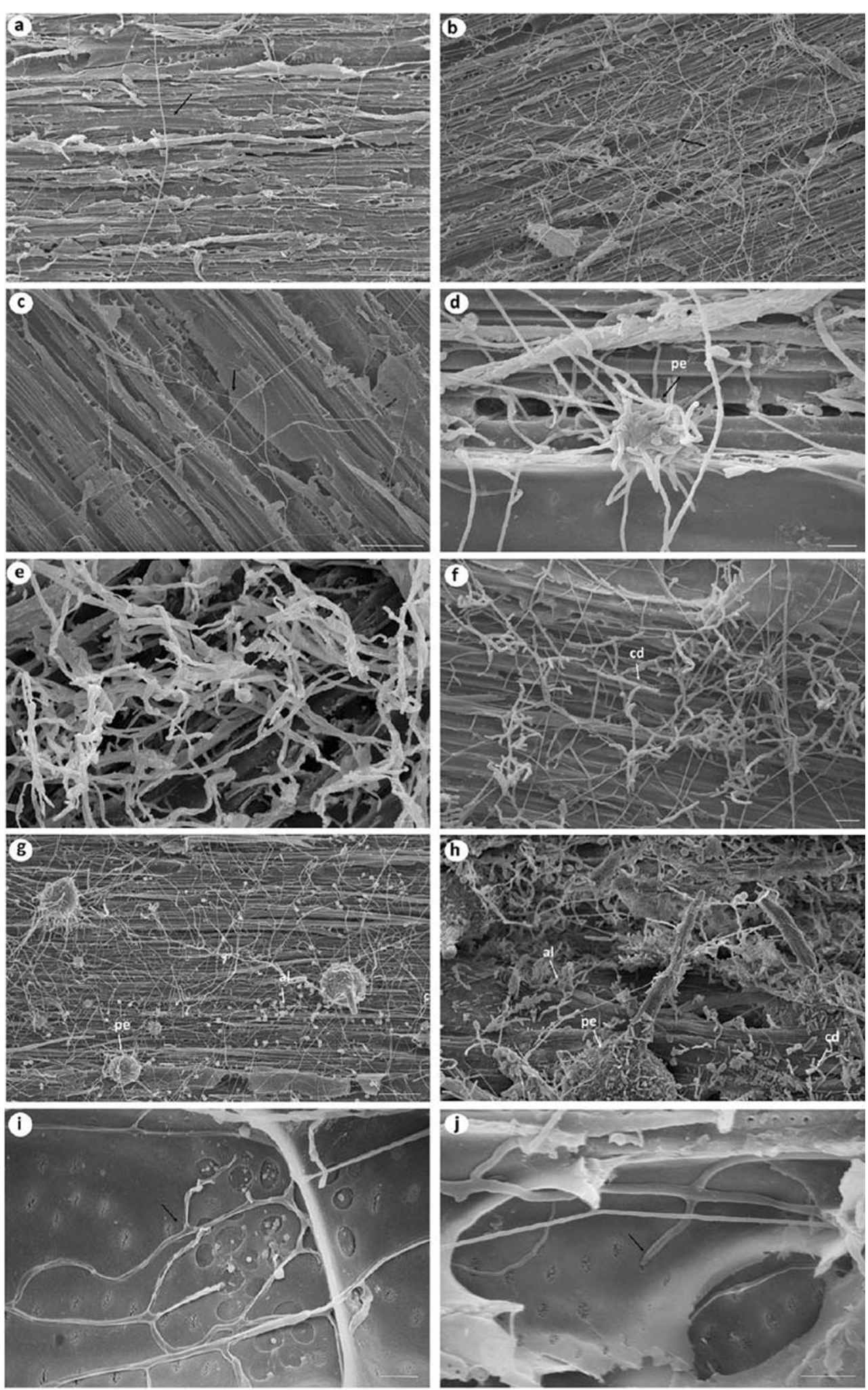


\section{Results}

\subsection{Symptoms evaluation}

Because no significant statistical difference occurred between the two inoculation experiments, data were combined, and the means from the treatments were used. At 60 dai, the mean lesion length on the stem of cuttings of the resistant clone was significantly smaller $(5.3 \mathrm{~cm})$ compared to the susceptible clone $(62.7 \mathrm{~cm})$, confirming the level of resistance of both clones to the SBS-1 isolate (Table 1). Additionally, unlike the inoculated resistant clone, all the cuttings of the inoculated susceptible exhibited wilting. The fungus was reisolated from the inoculation point of both clones.

\subsection{Lignin concentration}

The concentrations of insoluble, soluble, and total lignin were significantly increased by 20,29 , and $22 \%$, respectively, in the resistant cuttings inoculated with $C$. fimbriata compared with those in the wounded uninoculated cuttings from the resistant clone (Table 1 and Fig. 1). Inoculated cuttings of the susceptible clone exhibited a significant increase in the concentration of soluble lignin (by 28\%) compared with the wounded uninoculated cuttings. In contrast, the inoculated cuttings of the resistant clone showed the highest total lignin concentration compared to all the other treatments.

\subsection{Histological observations}

The tissues of the susceptible clone showed intense fungal colonization and sporulation (conidiophores containing conidia as well as aleuroconidia and perithecia) compared with those of the resistant clone (Figs. 1 and 2 ; and Figs. $4 \mathrm{a}-\mathrm{j}$ and 5 in the Appendix). At 12 to 36 hai, mycelial growth of the fungus was noticed on the stem tissue in both clones, although more mycelium growth was observed on the susceptible clone (Fig. 2a, b; and Fig. 4a-f in the Appendix). At 36 hai, perithecium formation (Fig. 1 and Fig. 2d) was observed, and at 48 hai, conidiophores were found on the susceptible clone (Fig. 1 and Fig. 2f) but not on the resistant clone (Fig. 1 and Fig. 2c, e). At 60 hai, perithecium formation, many aleuroconidia, and few conidiophores and conidia were observed on the resistant clone (Fig. 1 and Fig. 2g), whereas several perithecia, conidiophores, conidia, and aleuroconidia were detected on the susceptible clone (Fig. 1 and Fig. 2h).

Differences regarding fungal colonization inside of the stem tissue of the resistant and susceptible clones were also observed from 1 to 32 dai (Fig. 1; and Fig. 7 in the Appendix). In the susceptible clone, fungal hyphae rapidly colonized the stem tissue, whereas in the resistant clone, colonization was slow and essentially restricted to specific areas surrounding the inoculation point (Fig. 3e, f). At 1 dai, fungal hyphae were observed
Fig. 3 Histochemical and structural reactions in stem tissue sections of the CLR212 (resistant) (a, c, e, g, i, and k) and CLR240 (susceptible) (b, $\mathbf{d}, \mathbf{f}, \mathbf{h}, \mathbf{j}$, and l) clones of Eucalyptus urophylla $\times$ E. grandis. The samples were collected 24 (a, b, i, j, k, and l), 36 (c), and 48 (d, g, and h) h after inoculation and 32 days after inoculation (e and $\mathbf{f}$ ) with Ceratocystis fimbriata. The tissues were stained with toluidine blue (g and $\mathbf{h}$ ), ferric chloride (e, $\mathbf{f}, \mathbf{i}$, and $\mathbf{j})$, and lugol ( $\mathbf{k}$ and $\mathbf{l})$. Black arrows show amorphous material in contact with fungal hyphae (a), closed vessel pits with deposited amorphous material (c), and low fungal colonization and high deposition of phenolic compounds in the colonized tissues (e) in the resistant clone, the formation of tyloses and gels in xylem vessels in both clones ( $\mathbf{g}$ and $\mathbf{h}$ ), high deposition of phenolic compounds in the colonized tissues in the resistant clone compared to the susceptible clone (i and $\mathbf{j}$ ), and the deposition of starch and of oxalate crystals mainly in resistant clone $(\mathbf{k}$ and $\mathbf{l}) . t i=$ tyloses, $g e=$ gels, $f u=$ fungus, co $=$ calcium oxalate, and st $=$ starch. Scale bars $=2(\mathbf{c}), 10(\mathbf{a}, \mathbf{b}$, and $\mathbf{d})$, $20(\mathbf{e}, \mathbf{f}, \mathbf{i}$, and $\mathbf{j})$, and $100(\mathbf{g}, \mathbf{h}, \mathbf{k}$, and $\mathbf{l})$

in a few cells in the stem tissue of the resistant clone (Fig. 7a in the Appendix). In contrast, in the susceptible clone, the process of colonization initiated in the xylem vessels and in several cells of the adjacent tissues (Fig. 7b in the Appendix). At 2 and 4 dai, fungal colonization was restricted to the xylem vessels of the resistant clone (Fig. 7c and e in the Appendix), whereas in the susceptible clone, fungal hyphae colonized the xylem vessels and tissues adjacent to vessels and ray cells (Fig. $7 \mathrm{~d}$ and $\mathrm{f}$ in the Appendix). At 6 and 8 dai, in the resistant clone, fungal colonization remained restricted to the xylem vessels, with few fungal structures within the xylem vessels and aleuroconidia appeared as empty shells (Fig. $7 \mathrm{~g}$ and $\mathrm{i}$ in the Appendix). In contrast, in the susceptible clone, fungal hyphae colonized all tissues of the stem and several aleuroconidia, hyphae, and conidia within the xylem vessels were observed (Fig. $7 \mathrm{~h}$ and $\mathrm{j}$ in the Appendix). At 16 dai, the fungus colonized the tissues adjacent to the xylem vessels of the resistant clone (Fig. 7k in the Appendix), while for the susceptible clone, the xylem vessels were completely colonized by the fungus, causing obstruction and tissue degradation (Fig. 71 in the Appendix). At 32 dai, reduced fungal colonization in the tissues of the resistant clone was noted (Figs. 1 and 3e; and Fig. $7 \mathrm{~m}$ in the Appendix). Intense fungal colonization and degradation of all stem tissues were observed in the susceptible clone (Figs. 1 and 3f; and Fig. $7 \mathrm{n}$ in the Appendix).

A plant reaction to $C$. fimbriata infection was also observed (Fig. 1). A more rapid host response to fungal colonization was observed in the tissue of the resistant clone compared with the susceptible clone (Fig. 1). At 24 hai, amorphous material was observed in contact with fungal hyphae in the resistant clone (Figs. 1 and 3a), and at 48 hai, fungal hyphae appeared as empty shells in the resistant clone (Figs. 1 and 2e) but not in the susceptible clone (Figs. 1, 2f, and 3d). The observations of xylem vessels in the resistant clone showed that amorphous material also accumulated in areas surrounding fungal hyphae at 24 hai (Fig. 6a in the Appendix), and $12 \mathrm{~h}$ later, the fungal hyphae appeared as empty shells (Fig. 2i). The hyphae did not cross over the vessel pits to reach the parenchyma tissue, most 

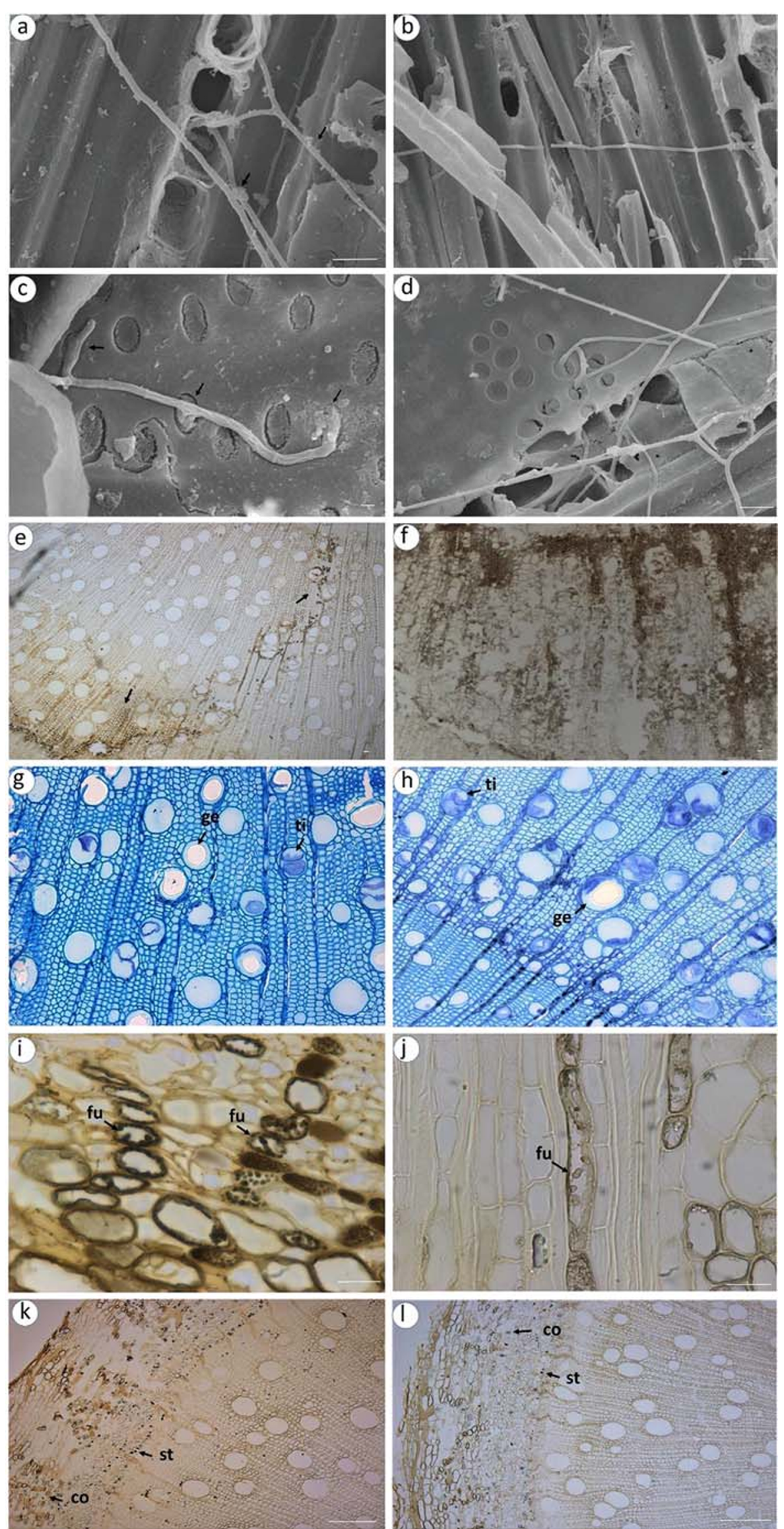

INRAC פ̂Springer 
likely due to closure of the vessel pits and the deposition of amorphous material (Fig. 3c). Accumulation of calcium oxalate and the formation of vesicles in the vessel pits, which most likely contained phenolic compounds, were also observed (Fig. 6d in the Appendix). The analysis of the susceptible clone showed that at 48 hai, amorphous material started deposition and hyphae appeared as empty shells (Fig. 1; and Fig. 6e in the Appendix); however, their levels were lower than those observed in the resistant clone (Fig. 1; and Fig. $6 \mathrm{~b}$ and $\mathrm{d}$ in the Appendix). Fungal penetration through the vessel pits and subsequent colonization of the parenchyma tissue were noted at 48 hai (Fig. 3d). In uninoculated cuttings of the resistant clone, the vessel pits were apparently closed, and the accumulation of amorphous material and the presence of calcium oxalate in the vessel pits and the xylem were observed (Fig. 1; and Fig. 6g in the Appendix). In contrast, in uninoculated cuttings of the susceptible clone, the vessel pits were partially closed, and less accumulation of amorphous material and calcium oxalate was detected (Fig. 1; and Fig. $6 \mathrm{~h}$ in the Appendix).

The formation of tyloses in the xylem vessels of inoculated and wounded uninoculated cuttings was observed at 1 dai (Figs. 1 and 3; and Figs. 7 and 8 in the Appendix). Tylose formation was not observed in the xylem vessels of the unwounded cuttings of both clones at any sampling time (Fig. 1; and Fig. 8e, f, k, l, q, and $r$ in the Appendix). The formation of gels in xylem vessels was observed in cuttings of both inoculated clones starting at 2 dai (Figs. 1 and 3; and Fig. 8g, h, m, and $\mathrm{n}$ in the Appendix), whereas no gels formed in the vessels of the wounded uninoculated cuttings and in the unwounded cuttings (Fig. 1; and Fig. 8c-f, i-1, and o-r in the Appendix).

Deposition of phenolics was also observed in the stem tissues of both clones after wounding and inoculation, but increased accumulation was detected especially in the resistant clone (Figs. 1 and 3i; and Figs. 7, 9, and 10 in the Appendix). At 1 dai, phenolics deposition was intense in the resistant clone, primarily in the periderm, in the rays, and near the pith, and the accumulation level remained high throughout the evaluation time (Fig. 9a, c, e, g, i, and k in the Appendix). Phenolics deposition was also observed around the colonization sites of the fungus in this clone (Fig. 3e, i; and Fig. 9c, e, $\mathrm{g}, \mathrm{i}$, and $\mathrm{k}$ in the Appendix). Even though phenolics deposition was noticed in inoculated plants of the susceptible clone, their deposition was lower in comparison to inoculated plants of the resistant clone (Figs. 1 and 3j; and Fig. 9b, d, f, h, j, and 1 in the Appendix). The phenolics deposition was also observed after wounding in the wounded uninoculated cuttings, and higher accumulation was detected in the resistant clone compared with the susceptible clone (Fig. 10 in the Appendix). The deposition of phenolics in unwounded cuttings of both clones was lower than that in wounded uninoculated or inoculated cuttings, particularly in the susceptible clone, where the deposition was concentrated in the periderm (Fig. 1; and Fig. 11 in the Appendix).
Calcium oxalate and starch were also observed in the stem tissue regardless of the clone and sampling time (Fig. 1). At 14 dai, increased deposition of starch in the periderm and phloem and of calcium oxalate was observed in both inoculated and wounded uninoculated clones compared with unwounded cuttings, although increased accumulation levels were observed in the resistant clone (Figs. 1 and 3k; and Figs. 12a-f, 13a-f, and 14a-f in the Appendix). At 8 and 16 dai, starch deposition was observed in the ray cells near the fungal structures in the resistant clone (Fig. 12g and i in the Appendix), and no accumulation was observed in the susceptible clone (Fig. 12h and $\mathrm{j}$ in the Appendix). Wounded cuttings of the resistant clone accumulated starch in the ray cells and in the periderm as well as calcium oxalate in the periderm, whereas in the susceptible clone, starch and calcium oxalate deposition was observed in the periderm (Fig. 13g-j in the Appendix). Unwounded cuttings of both clones showed calcium oxalate and starch deposition in the periderm (Fig. $14 \mathrm{~g}-\mathrm{j}$ in the Appendix). At 32 dai, starch deposition was observed in the rays and near the pith in the resistant clone, but the accumulation of starch in the susceptible clone could not be observed due to massive tissue degradation (Fig. 12k and 1 in the Appendix). Wounded plants of the resistant clone showed starch deposition in the rays (Fig. 13k in the Appendix), but in the susceptible clone, starch deposition was primarily observed in the periderm (Fig. 131 in the Appendix). In unwounded cuttings, starch and calcium oxalate deposition occurred only in the periderm, although the accumulated levels were lower than those found in wounded uninoculated and inoculated cuttings of both clones (Fig. 14k and 1 in the Appendix).

\section{Discussion}

The results obtained in the present study confirmed that defense reactions of the two clones to wounding and in response against fungal infection were essentially the same, although cuttings from the resistant clone exhibited rapid and intense defense mechanisms that efficiently impaired the colonization of $C$. fimbriata in the stem tissues, which can involve closure of the vessel pits; intense formation of tyloses and gels; the accumulation of amorphous material, starch, phenolic compounds, and calcium oxalate; and lignification. In contrast, the fungus colonizes all stem tissues of the susceptible clone, resulting in rapid wilting, as previously observed in other resistant and susceptible clones of eucalypt to Ceratocystis wilt (Acelino Couto Alfenas, personal information, 2018; Oliveira et al. 2015). Eynck et al. (2009) investigated the Verticillium longisporum-oilseed rape interaction and observed that resistant and susceptible genotypes exhibited the same reactions to fungal infection and that the intensity of the response in the resistant genotype was higher than that of the susceptible 
genotype. The efficacy of plant defense mechanisms against vascular disease-causing pathogens depends on the ability of the plant to rapidly activate mechanisms that limit vascular colonization by the pathogen (Hammond-Kosack and Jones 1996). Rapid and intense defense reactions have also been observed for plants of Platanus acerifolia and Theobroma cacao after infection with Ceratocystis spp. (Clérivet et al. 2000; Santos et al. 2013).

Fungal colonization in the resistant clone was mostly restricted to the xylem vessels, and colonization of the parenchyma tissues occurred only at advanced stages of fungal infection. In the resistant clone, the closure of vessel pits and the deposition of phenolics and amorphous substances might have formed physical and biochemical barriers to prevent invasion of the fungus in the parenchyma tissue. Other studies have also reported the limited colonization of fungi to a specific site in xylem vessels (Clérivet et al. 2000; Chen et al. 2004; Santos et al. 2013). Unlike the resistant clone, the vessel pits of the susceptible clone were open, which allowed fungal hyphae to reach the parenchyma and adjacent tissues. According to the results obtained in the present study, $C$. fimbriata hyphae colonized all stem tissues of the susceptible clone cuttings and should not be considered a pathogen that exclusively targets the vascular system. Hyphae of C. fimbriata f. sp. platani, Leptographium guttulatum, Ophiostoma olivaceapinii, and Ceratocystis smalleyi also passed through the vessel pits to colonize the axial and radial parenchyma cells due to their being nutrient-rich (Clérivet and El Modafar 1994; Park and Juzwik 2014; Pérez-Vera et al. 2011). Stria-like lesions (characteristic symptom of the presence of $C$. fimbriata) might be due to the presence of the fungus in the rays and to the accumulation of oxidized phenolic compounds in this area. The intercalated (noncontinuous vertically) browning of the inner stem tissues of the susceptible clone was most likely due to the translocation of reproductive structures of the fungus in the xylem vessels via water flow to specific locations, where the structures then initiate new infections. It is likely that the barriers in the xylem vessels in the susceptible clone were unable to prevent pathogen colonization from the site inoculation.

Many conidia of $C$. fimbriata were observed in the stem tissues of the susceptible clone at the beginning of the fungal infection process. The production of conidia during the early stages of colonization might be the key to the rapid dispersion of the fungus in plant tissues (Duncan and Himelick 1988; Firmino et al. 2015). In the resistant clone, many aleuroconidia were observed, which indicated their role as resistance structures that allow the fungus to survive under adverse conditions. Nevertheless, the highest production of aleuroconidia was observed in xylem vessels of both clones most likely because this type of cell is composed of raw sap (Ioannou et al. 1977). In contrast to the results obtained in the present study, abundant hyphae of $C$. smalleyi were found in the axial and radial parenchyma, fibers, and xylem of
C. cordiformis plants, but no fungal sporulation was detected (Park and Juzwik 2014). Another important fact observed was that the defense mechanisms of both clones were not lethal to the pathogen, probably due to the formation of fungal resistance structure (aleuroconidia) increasing the amount of pathogen inoculum for a new culture cycle.

Regarding host defense responses against $C$. fimbriata infection, increased tylose formation in vessel elements with intense staining indicating the inclusion of phenolic compounds and amorphous material was also observed in inoculated and wounded uninoculated cuttings of both clones. Tyloses constitute a response to wounding or infection with fungi or bacteria (Kuroda 1991; Sun et al. 2007), and their formation is a nonspecific reaction of plants that forms a physical barrier to restrict pathogen colonization. In vascular diseases, tyloses are considered a primary defense mechanism that involves partial or total occlusion of the xylem vessels to limit pathogen spread (Clérivet et al. 2000; Rioux et al. 1998). The contribution of tyloses to the host defense strategy against vascular pathogens is associated with the production of occlusion materials such as gels and gums (Beckman 1987; Kpémoua et al. 1996). In the present study, the presence of gel in xylem vessels was only observed in the stem tissues of both inoculated cuttings. In another study, gel accumulation was not observed in the vessels of Carya cordiformis plants that were only injected with water (Park and Juzwik 2014). The formation of gels in xylem vessels of plants infected with vascular pathogens might be induced by the swelling of vessel pits, materials secreted by parenchyma cells adjacent to the vessels, and the action of pectinolytic enzymes produced by pathogens (Ouellette and Rioux 1992; Rioux et al. 1998).

In addition to the production of tyloses and gels in xylem vessels, the resistant clone showed intense deposition of amorphous material in adjacent parenchyma cells, which were densely stained with toluidine blue. The composition of this material was not determined in the present study, but other studies have identified these compounds as phytoalexins and terpenoids, which were found to be accumulated in xylem vessels and adjacent parenchymal cells of a cotton cultivar resistant to Fusarium oxysporum f. sp. vasinfectum (Hall et al. 2011) and in mango plants colonized by C. fimbriata (Araujo et al. 2014).

In the present study, the deposition of phenolics was observed mainly in the stems of the resistant clone. Pimenta et al. (2017) reported higher accumulation of phenolics in resistant compared with susceptible clone of eucalypt infected with $C$. fimbriata. In our study, histopathological examinations of stem sections showed the accumulation of phenolics in the parenchyma and adjacent xylem cells, in the periderm, in the rays, in tissues near the marrow, and in areas surrounding the fungal structures. Phenolics deposited in parenchyma cells act as a barrier against the colonization of pathogens as reported for the Fusarium oxysporum f. sp. vasinfectum-cotton, C. fimbriata-mango, and C. manginecans-acacia (Araujo 
et al. 2014; Araujo et al. 2016; Hall et al. 2011; Shi et al. 1992; Trang et al. 2018) interactions. In addition to their antimicrobial action, phenolics are associated with cell wall strengthening (Tuncel and Nergiz 1993), the modulation of plant hormones involved in defense signaling, the catalysis of reactive oxygen species (Dixon and Paiva 1995), and the synthesis of lignin (Eynck et al. 2009). The deposition of phenolics in the bark might constitute a preformed response to restrict the penetration of $C$. fimbriata in the sapwood considering that this reaction was also observed in unwounded and noninoculated cuttings. However, it is induced and strongly intensified in wounded and inoculated cuttings compared with the control cuttings.

The rapid production of phenolics and the consequent synthesis of lignin increase the host's efficiency to limit pathogen colonization (Eynck et al. 2009) as noticed for plants from the resistant clone in the present study. Lignin is an important structural component of plant tissues that plays a key role in mechanical support, solute conductance, and disease resistance (Harakava 2005; Humphreys and Chapple 2002; Whetten and Sederoff 2004). Additionally, lignin deposition likely hinders the diffusion of lytic enzymes and nonselective toxins produced by the pathogen (Vance et al. 1980). Other studies have also observed higher lignin deposition in the tissues of resistant cultivars of lentil (Lens culinaris), carnation (Dianthus caryophyllus), and oilseed rape colonized by Fusarium oxysporum f. sp. lentis, Fusarium oxysporum f. sp. dianthi, and Verticillium longisporum, respectively, compared with what was found in susceptible cultivars (Eynck et al. 2009; Niemann et al. 1990; Pouralibaba et al. 2017).

Calcium oxalate was observed in the periderm in the stems of both clones, but these crystals were abundantly observed in the xylem specimens, particularly in the resistant clone at the initial stages of infection. According to Datnoff et al. (2007), an increase in the accumulation of calcium in plant tissues might increase resistance to infection with vascular pathogens. Araujo et al. (2014) found increased calcium deposition in the stem tissues of mango plants of cultivars resistant to C. fimbriata, which delayed the wilting of the plants.

Another response to $C$. fimbriata infection was starch accumulation over time, particularly in the resistant clone that showed high starch deposition, primarily in the ray cells located near the fungal structures. Silva et al. (2018) reported that plants from a resistant eucalypt clone showed a rapid increase in sugar concentration (e.g., erythritol, arabinose, isomaltose, cellobiose, gentiobiose, maltitol, melibiose, xylulose, and turanose) in their tissues after inoculation with C. fimbriata compared with the susceptible clone. The ability of plants to respond to infection by pathogenic fungi is associated with the amount of carbohydrates allocated to the activation of defense mechanisms (Viiri et al. 2001). Phenolics are derived from carbohydrates via the shikimate pathway, through which approximately one fifth of all carbon is fixed by plant flows (Matsuki 1996).
The results of the present study are of extreme importance to advance our understanding of the Eucalyptus - C. fimbriata interaction. This study was the first to present broader results of the $C$. fimbriata colonization process in resistant and susceptible eucalypts clones over time and the defense responses presented by these clones. Moreover, the information provide here can be used in a breeding program to obtain clones of eucalypts more resistant to Ceratocystis wilt considering the remarkable difference existing between resistant and susceptible cuttings in terms of defense strategies orchestrated by them to respond against fungal infection.

\section{Conclusions}

The results of the present study allow us to conclude the following:

(a) The resistance of eucalypts plants to Ceratocystis wilt was not only related to the ability of the plant to accumulate lignin in its tissues, as previously reported. Instead, the resistance of eucalypt to Ceratocystis wilt is based on rapid and intense defense responses that limit the colonization of $C$. fimbriata in host tissues, which can involve closure of the vessel pits; intense formation of tyloses and gels; the accumulation of amorphous material, starch, phenolic compounds, and calcium oxalate; and lignification.

(b) The defense mechanisms of plants from the resistant clone were not lethal to the fungus.

(c) Ceratocystis fimbriata is not a pathogen that exclusively colonizes the vascular system, and stem lesions in the form of striations are due to fungal colonization and the response of the ray tissues in the cuttings.

(d) The high number of aleuroconidia found in the stem tissues of the resistant clone might be important for fungal survival under adverse conditions and cause new infections in the field.

Acknowledgments The authors are grateful for the assistance provided by the "Núcleo de Microscopia e Microanálise" and "Laboratório de Celulose e Papel" at UFV, to Professors Jorge Colodette and Edgard Augusto de Toledo Picoli, and to "CLONAR Resistência a Doenças Florestais" for providing the cutting material used in this study.

Funding information This research was financially supported by the Fundação de Amparo à Pesquisa do Estado de Minas Gerais (FAPEMIG), the Conselho Nacional de Desenvolvimento Científico e Tecnológico (CNPq), and the Suzano Papel e Celulose S.A. This study was financed in part by the Coordenação de Aperfeiçoamento de Pessoal de Nível Superior - Brasil (CAPES) - Finance Code 001.

Data availability The datasets generated and/or analyzed during the current study are available in the Zenodo repository (Silva et al. 2020) at https://doi.org/10.5281/zenodo.3616121. 


\section{Compliance with ethical standards}

\section{Appendix}

Conflict of interest The authors declare that they have no conflict of interest.

Fig. 4 Scanning electron micrographs of stem tissues of plants of the CLR212 (resistant) (R) and CLR240 (susceptible) (S) Eucalyptus urophylla $\times$

E. grandis clones colonized by Ceratocystis fimbriata. The micrographs were obtained 12 (a and b), 24 (c and d), 36 (e and f), 48 (g and $\mathbf{~ h}$ ), and 60 (i and j) h after inoculation. Arrows show the conidia germination ( $\mathbf{a}$ and $\mathbf{b}$ ), the formation of conidiophores in the susceptible clone (h), the formation of perithecia in the resistant clone (i), and fully formed perithecia in the susceptible clone $(\mathbf{j})$. Scale bars $=$ $10(\mathbf{a}, \mathbf{b}$, and $\mathbf{i}), 20(\mathbf{c}, \mathbf{h}$, and $\mathbf{j}), 30$ (d), and $100 \mu \mathrm{m}(\mathbf{e}-\mathbf{g})$
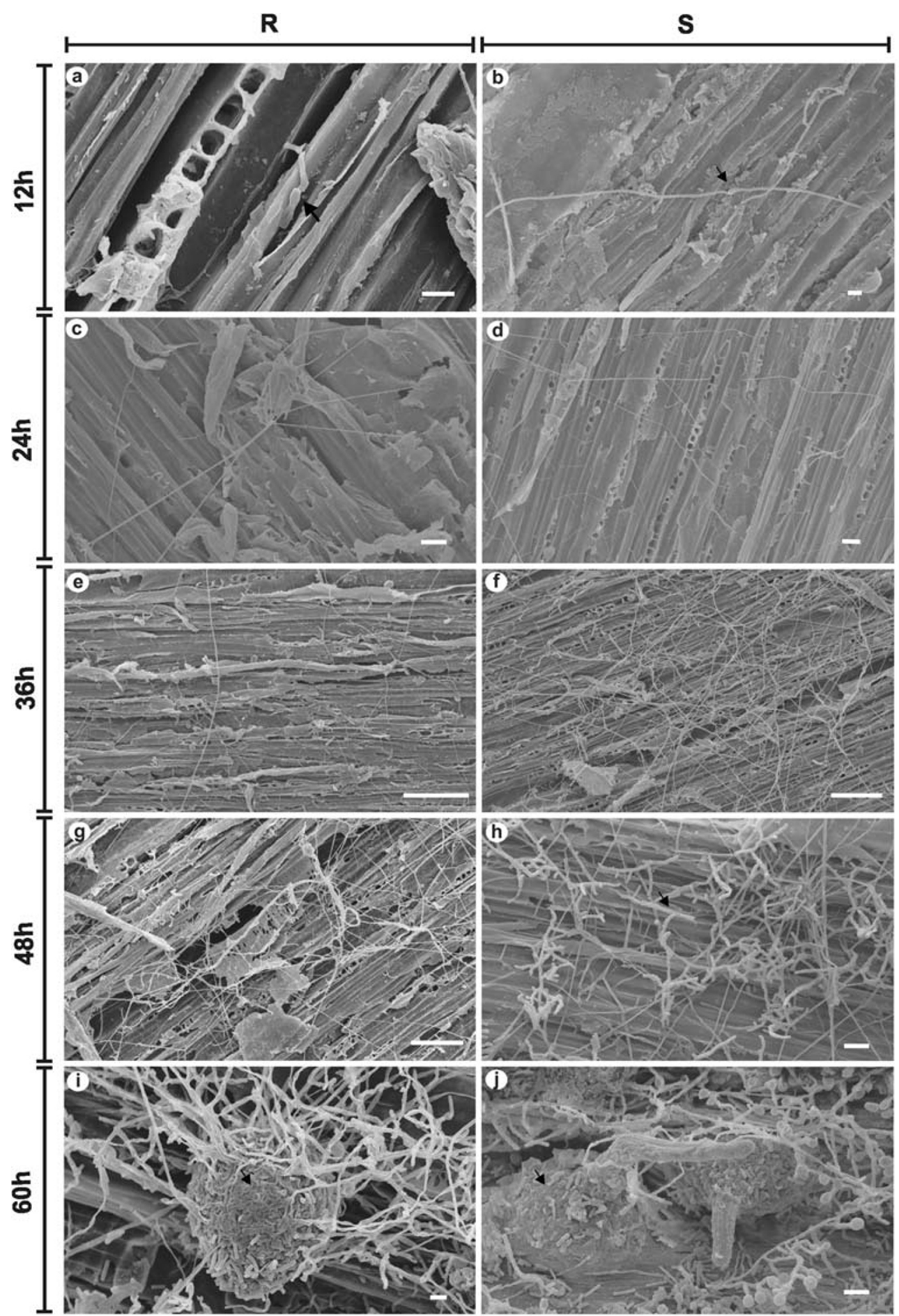
Fig. 5 Scanning electron micrographs of stem tissues of plants of the CLR212 (resistant) (R) and CLR240 (susceptible) (S) Eucalyptus urophylla $\times$

E. grandis clones colonized by Ceratocystis fimbriata. The micrographs were obtained 24 (a and $\mathbf{b}), 36$ (c and d), 48 (e and f), and 60 (g and $\mathbf{h}) \mathrm{h}$ after inoculation. Black arrows show amorphous material in contact with fungal hyphae in the resistant clone (a), the formation of perithecia (d) and conidiophores (f) in the susceptible clone, fungal hyphae that appeared as empty shells in the resistant clone (e), and abundant aleuroconidia (g) and fully formed perithecia (h) in the resistant and susceptible clones, respectively. Scale bars = $10(\mathbf{a}-\mathbf{c})$ and $20 \mu \mathrm{m}(\mathbf{d}-\mathbf{h})$

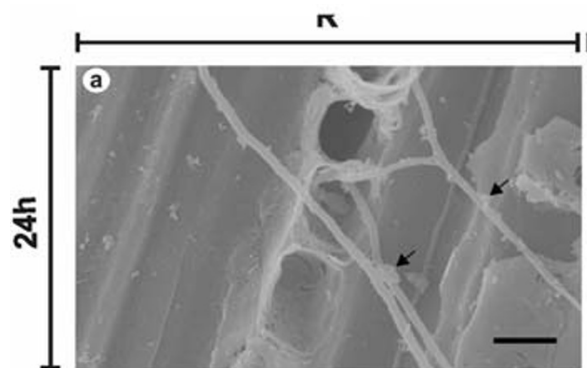

S
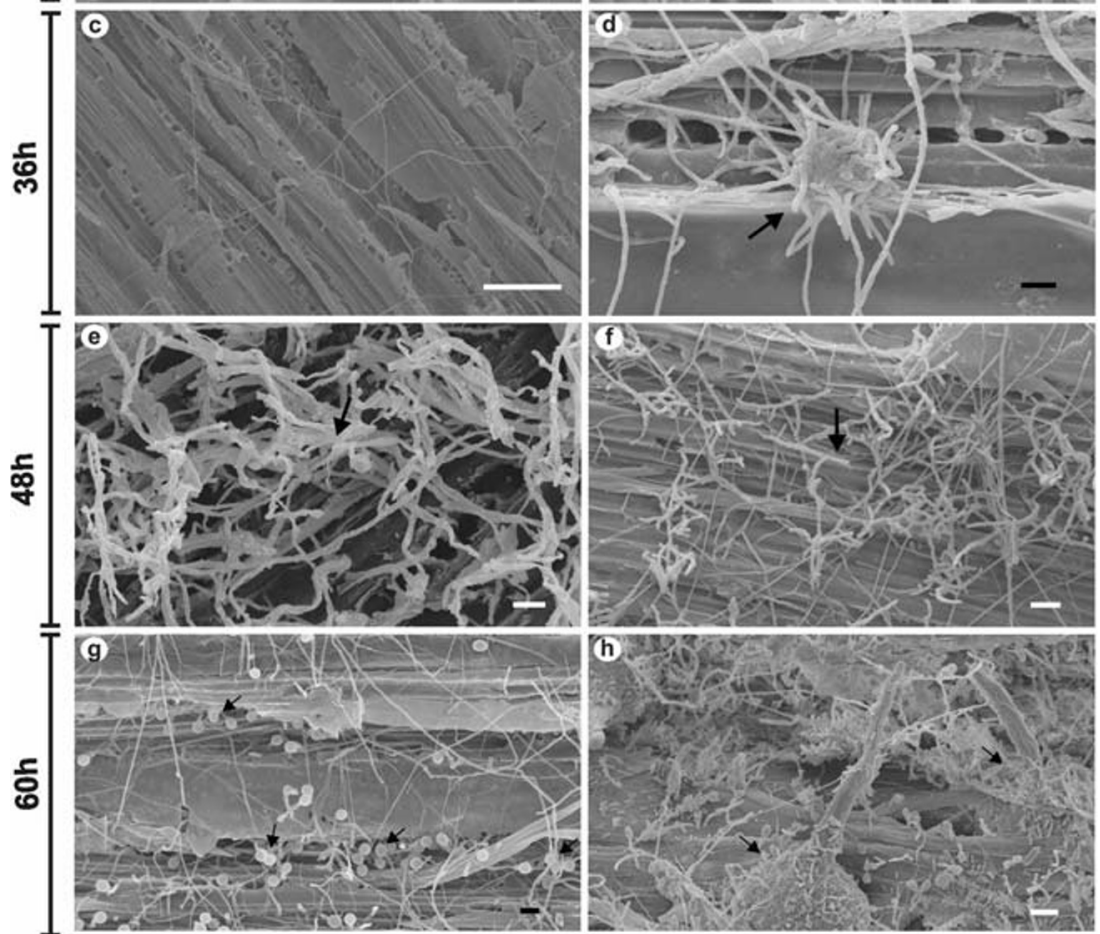
Fig. 6 Scanning electron micrographs of xylem tissues of the CLR212 (resistant) (a-d and g) and CLR240 (susceptible) (e, f, and $\mathbf{h}$ ) clones of Eucalyptus urophylla $\times E$. grandis. The micrographs were obtained 24 (a), 36 (b-d), and 48 (e and f) $\mathrm{h}$ after inoculation with Ceratocystis fimbriata and from uninoculated plants ( $\mathbf{g}$ and $\mathbf{h}$ ).

Black arrows show amorphous material in contact with fungal hyphae (a and e), hyphal wilting (b and e), crystal deposition and vesicle formation in vessel pits (b and d), and closed vessel pits with deposited amorphous material (c). $\mathrm{am}=$ amorphous material, $\mathrm{ve}=$ vesicles, and co $=$ calcium oxalate. Scale bars $=10(\mathbf{a}, \mathbf{b}, \mathbf{d}-$ h) and $2 \mu \mathrm{m}(\mathbf{c})$
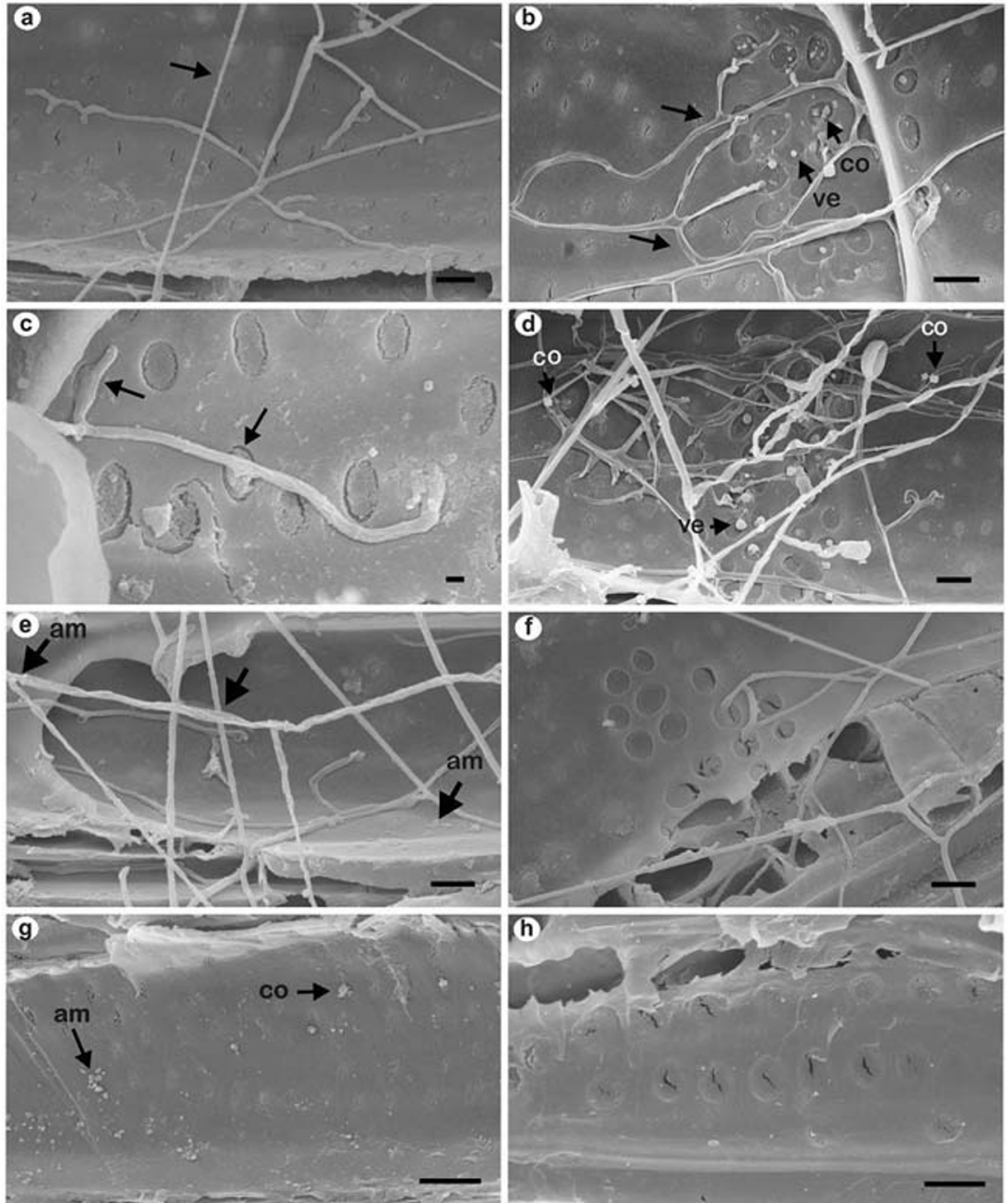
Fig. 7 Colonization of stem tissues of the CLR212 (resistant) (R) and CLR240 (susceptible) (S) clones of Eucalyptus urophylla $\times$ E. grandis at 1 (a and b), 2 (c and d), 4 (e and f), 6 (g and $\mathbf{h}$ ), 8 (i and j), 16 (k and $\mathbf{l}$ ), and 32 (m and $\mathbf{n}$ ) days after inoculation with Ceratocystis fimbriata. The tissues were stained with ferric chloride (a, b, $\mathbf{g}, \mathbf{h}, \mathbf{m}$, and $\mathbf{n})$ and toluidine blue $(\mathbf{c}-\mathbf{f}, \mathbf{i}-\mathbf{l})$. Black arrows show fungal colonization $(\mathbf{a}-\mathbf{k})$ and gel formation within xylem vessels $(\mathbf{c}-\mathbf{j})$, and black circles show high deposition of phenolic compounds in the colonized tissues in the resistant clone. $\mathrm{fu}=$ fungus and $\mathrm{ge}=$ gels. Scale bars $=20(\mathbf{a}-\mathbf{d}, \mathbf{g}, \mathbf{h}, \mathbf{j}, \mathbf{k}, \mathbf{m}$, and $\mathbf{n})$ and $50 \mu \mathrm{m}(\mathbf{e}, \mathbf{f}, \mathbf{i}$, and $\mathbf{l})$
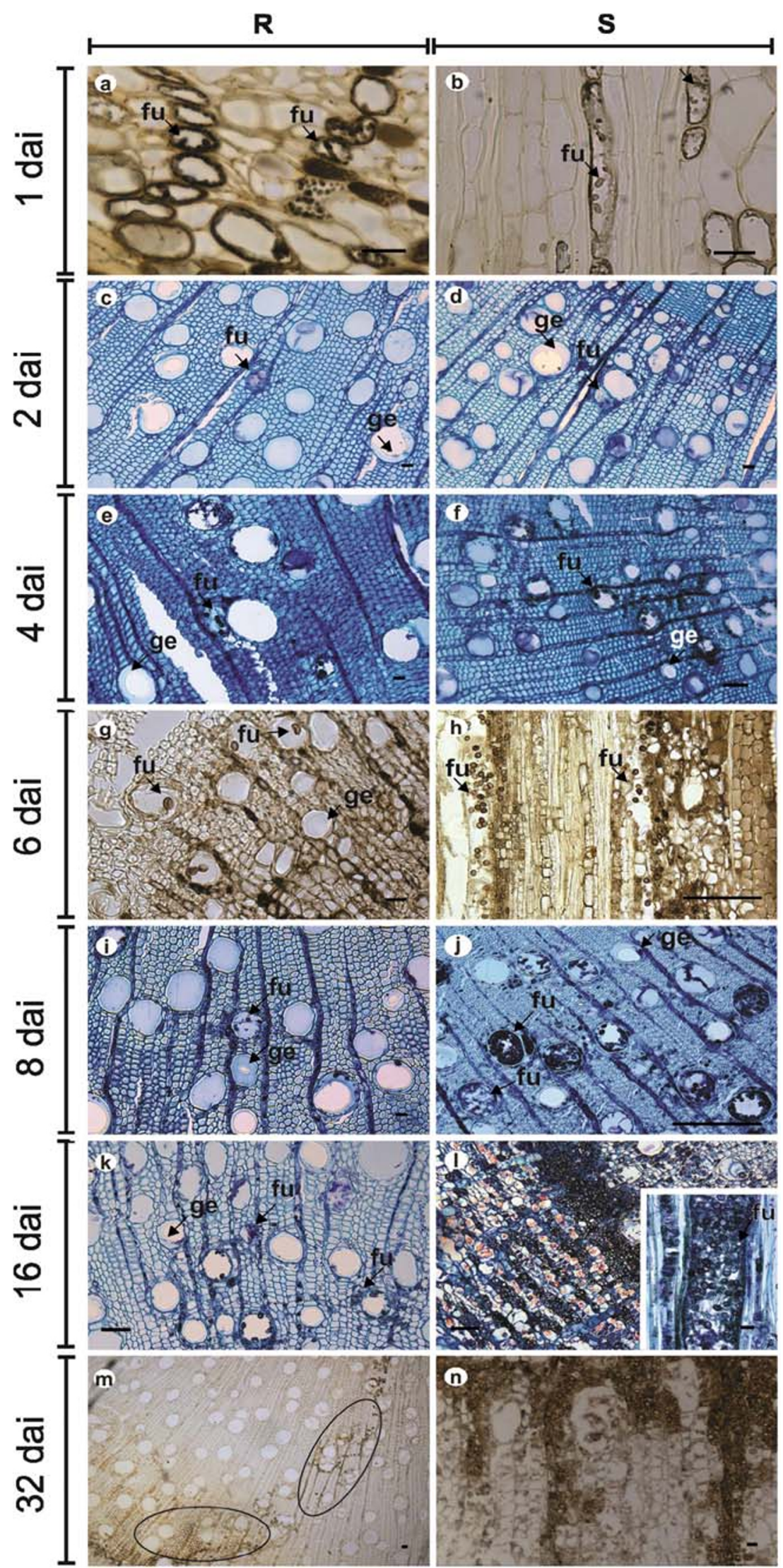

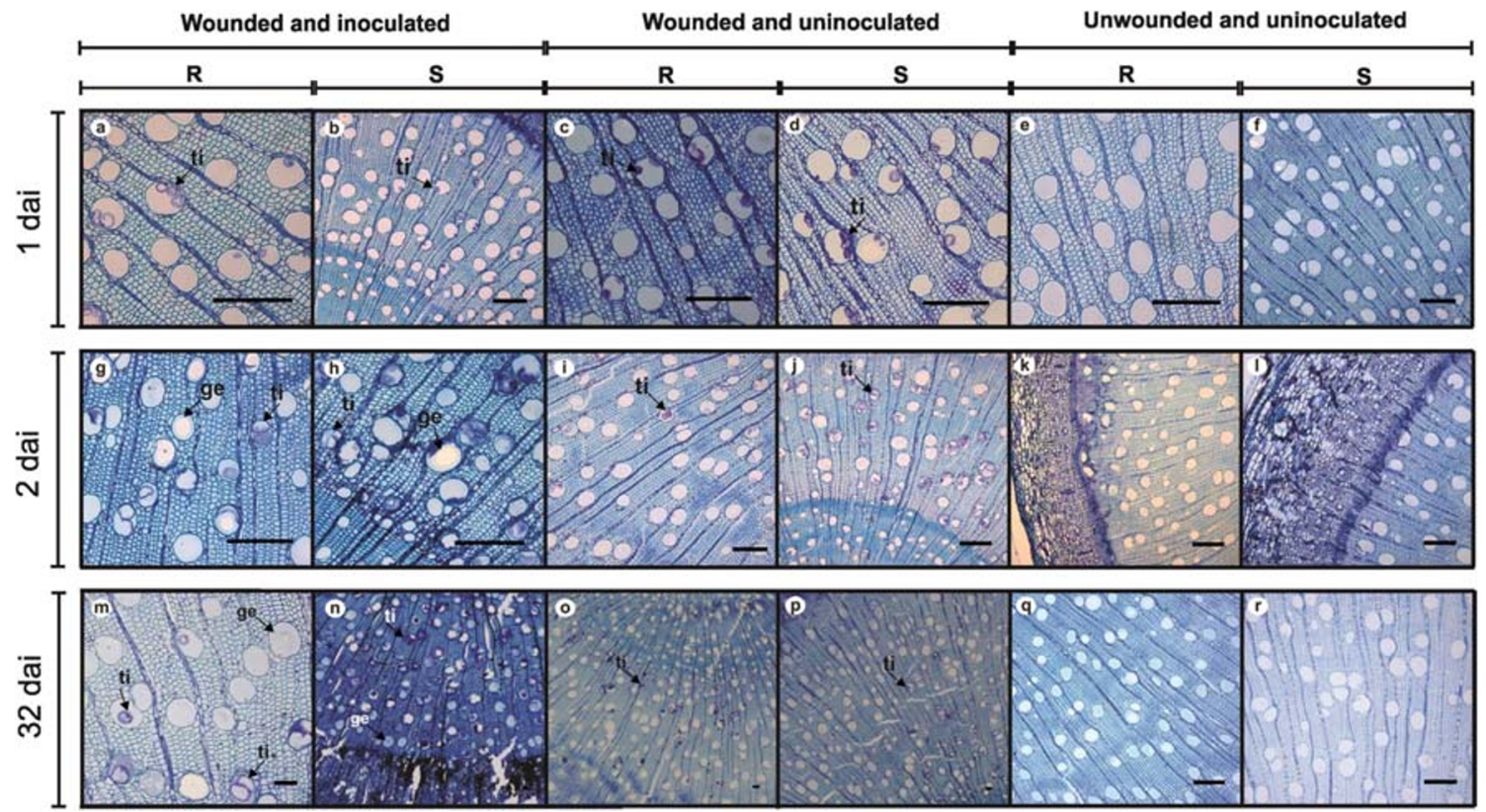

Fig. 8 Histochemical reactions in stem tissue sections of the CLR212 (resistant) (R) and CLR240 (susceptible) (S) clones of Eucalyptus urophylla $\times E$. grandis. The samples were collected 1 (a and $\mathbf{b}), 2$ (g and $\mathbf{h}$ ), and 32 ( $\mathbf{m}$ and $\mathbf{n}$ ) days after inoculation (dai) with Ceratocystis fimbriata; 1 (c and $\mathbf{d}), 2$ (i and $\mathbf{j}$ ), and 32 (o and $\mathbf{p}$ ) days after wounding; and from unwounded plants subjected to the same treatments $(\mathbf{e}, \mathbf{f}, \mathbf{k}, \mathbf{l}, \mathbf{q}$, and $\mathbf{r}$ ) and stained with toluidine blue. Black arrows show the formation of tyloses and gels in xylem vessels. ti $=$ tyloses and ge $=$ gels. Scale bars $=100(\mathbf{a}-\mathbf{l}, \mathbf{q}$, and $\mathbf{r})$ and $50 \mu \mathrm{m}(\mathbf{m}-\mathbf{p})$
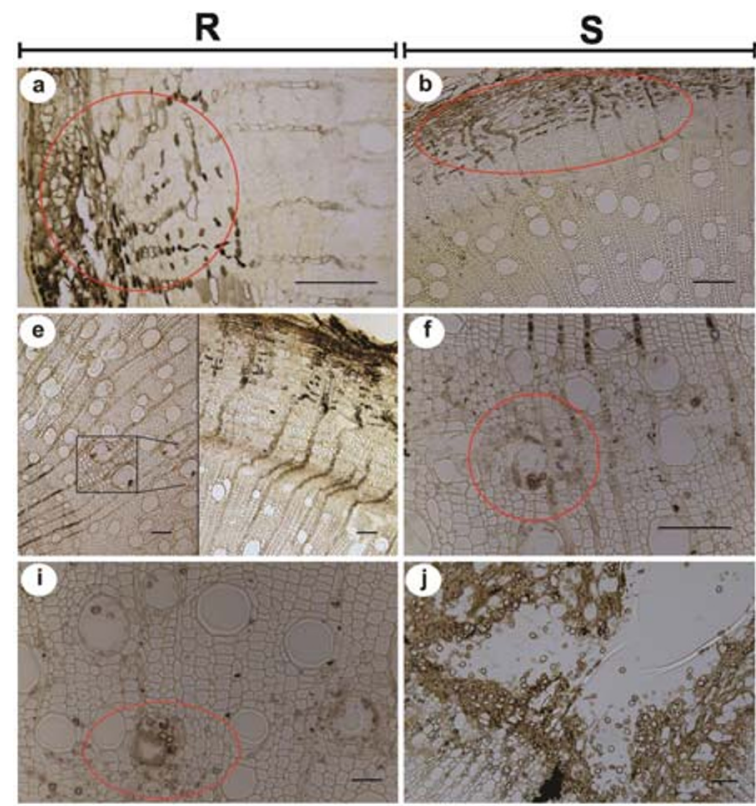

Fig. 9 Histochemical reactions in stem tissue sections of the CLR212 (resistant) (R) and CLR240 (susceptible) (S) clones of Eucalyptus urophylla $\times E$. grandis. The samples were collected 1 (a and $\mathbf{b}), 2(\mathbf{c}$ and $\mathbf{d}$ ), 4 (e and $\mathbf{f}$ ), 8 (g and $\mathbf{h}$ ), 16 (i and $\mathbf{j}$ ), and 32 (k and $\mathbf{l}$ ) days after inoculation with Ceratocystis fimbriata and stained with ferric chloride.

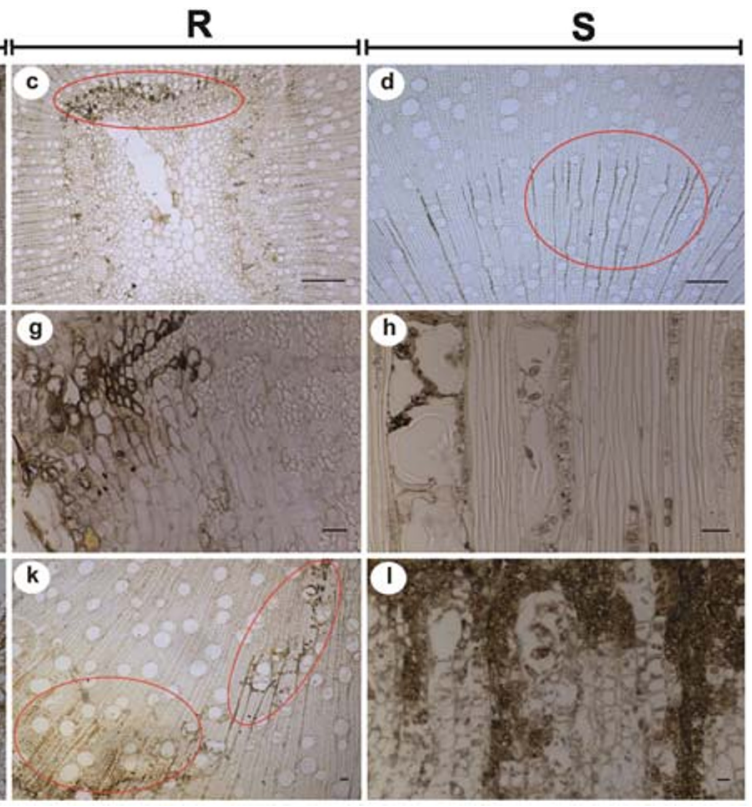

Red circles show phenolic compounds accumulated in the periderm (a and $\mathbf{b})$, around the pith (c), in the rays (d), and in the fungal colonization sites $(\mathbf{f}, \mathbf{i}$, and $\mathbf{k})$. Scale bars $=100(\mathbf{a}-\mathbf{d}$ and $\mathbf{f}), 50(\mathbf{e}$ and $\mathbf{g}-\mathbf{k})$, and $20 \mu \mathrm{m}$ (I) 


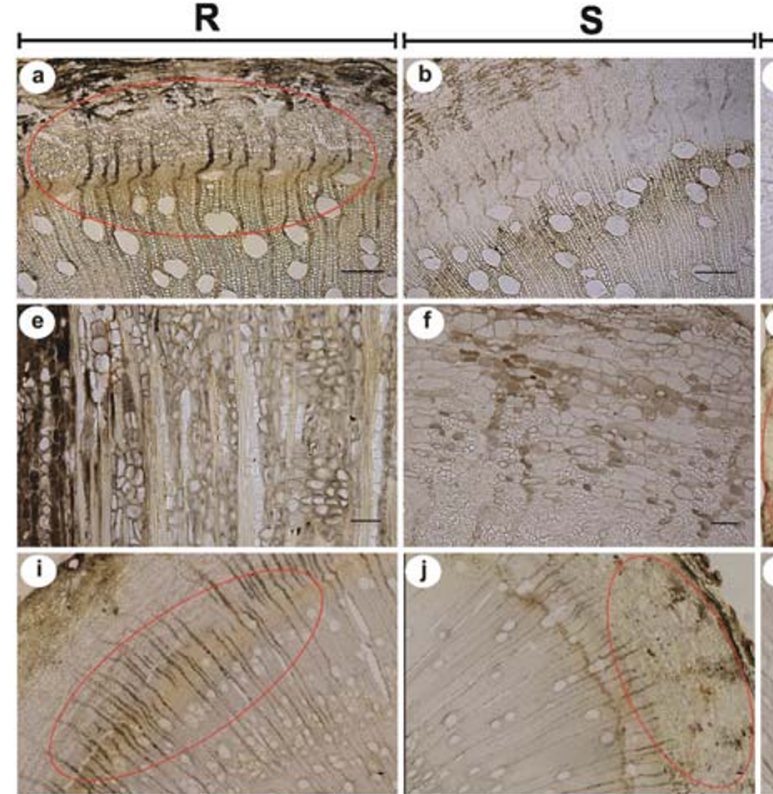

Fig. 10 Histochemical reactions in stem tissue sections of the CLR212 (resistant) (R) and CLR240 (susceptible) (S) clones of Eucalyptus urophylla $\times E$. grandis. The samples were collected 1 (a and $\mathbf{b}), 2$ (c and $\mathbf{d}$ ), 4 (e and $\mathbf{f}$ ), 8 (g and $\mathbf{h}$ ), 16 (i and $\mathbf{j}$ ), and 32 (k and $\mathbf{l}$ ) days after

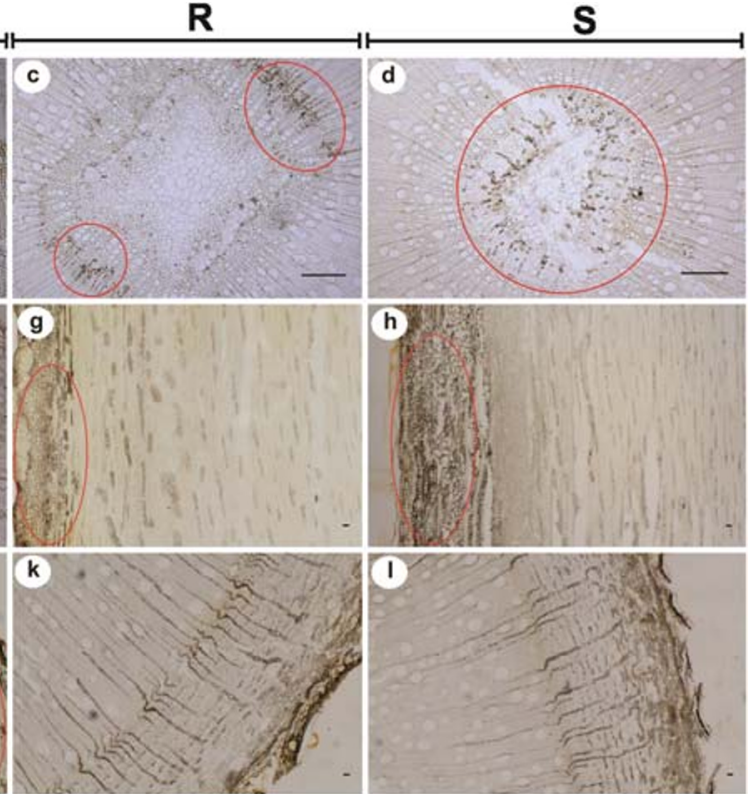

wounding and stained with ferric chloride. Red circles show phenolics deposition in the periderm ( $\mathbf{a}, \mathbf{g}, \mathbf{h}$, and $\mathbf{j})$, around the pith ( $\mathbf{c}$ and $\mathbf{d})$, and in the rays (i). Scale bars $=100(\mathbf{a}-\mathbf{d})$ and $50 \mu \mathrm{m}(\mathbf{e}-\mathbf{l})$

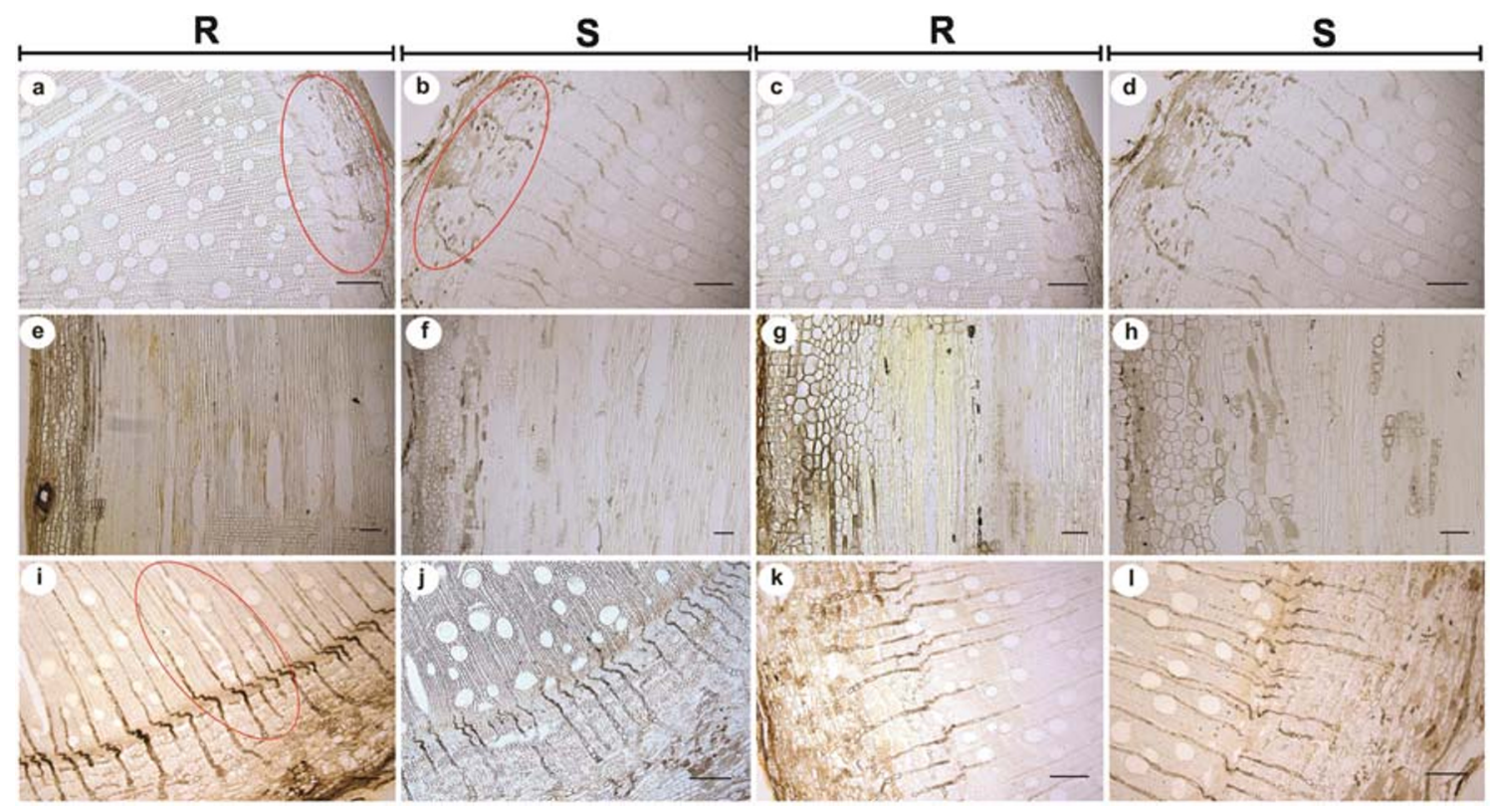

Fig. 11 Histochemical reactions in stem tissue sections of the CLR212 (resistant) (R) and CLR240 (susceptible) (S) clones of Eucalyptus urophylla $\times E$. grandis. The samples were collected from unwounded plants at 1 (a and b), 2 (c and d), 4 (e and f), 8 (g and $\mathbf{h}), 16$ (i and j), and 32 days ( $\mathbf{k}$ and $\mathbf{l}$ ) and stained with ferric chloride. Red circles show phenolics deposition in the periderm (a and $\mathbf{b}$ ) and in the rays (i). Scale bars $=100(\mathbf{a}-\mathbf{d}$ and $\mathbf{j}-\mathbf{I})$ and $50 \mu \mathrm{m}(\mathbf{e}-\mathbf{i})$ 


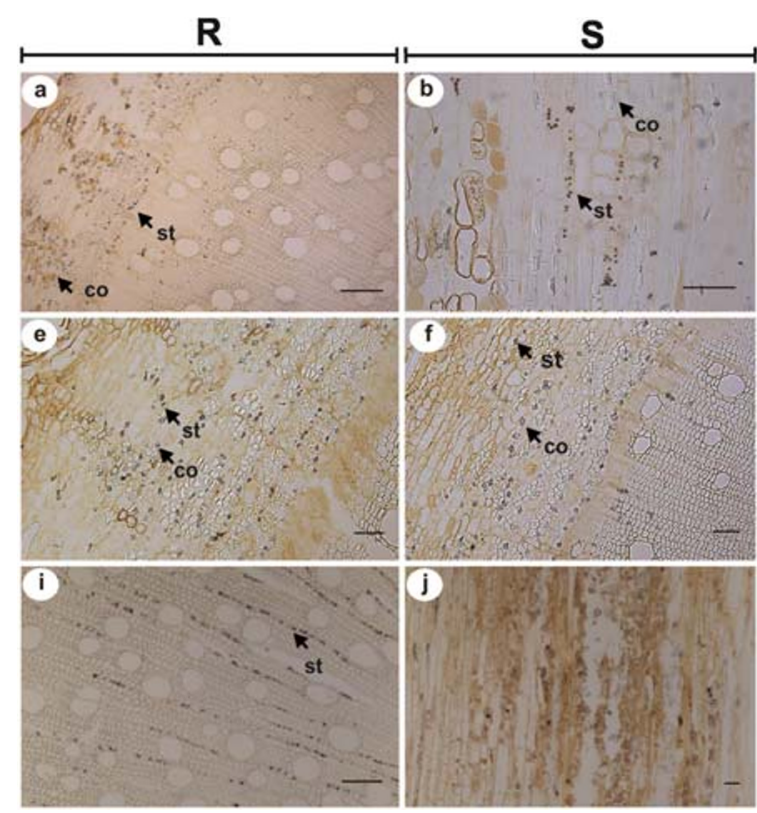

Fig. 12 Histochemical reactions in stem tissue sections of the CLR212 (resistant) (R) and CLR240 (susceptible) (S) clones of Eucalyptus urophylla $\times E$. grandis. The samples were collected 1 (a and $\mathbf{b}), 2(\mathbf{c}$ and $\mathbf{d}$ ), 4 (e and $\mathbf{f}$ ), 8 (g and $\mathbf{h}$ ), 16 (i and $\mathbf{j}$ ), and 32 (k and $\mathbf{~ ) ~ d a y s ~ a f t e r ~}$ inoculation with Ceratocystis fimbriata and stained with lugol. Black

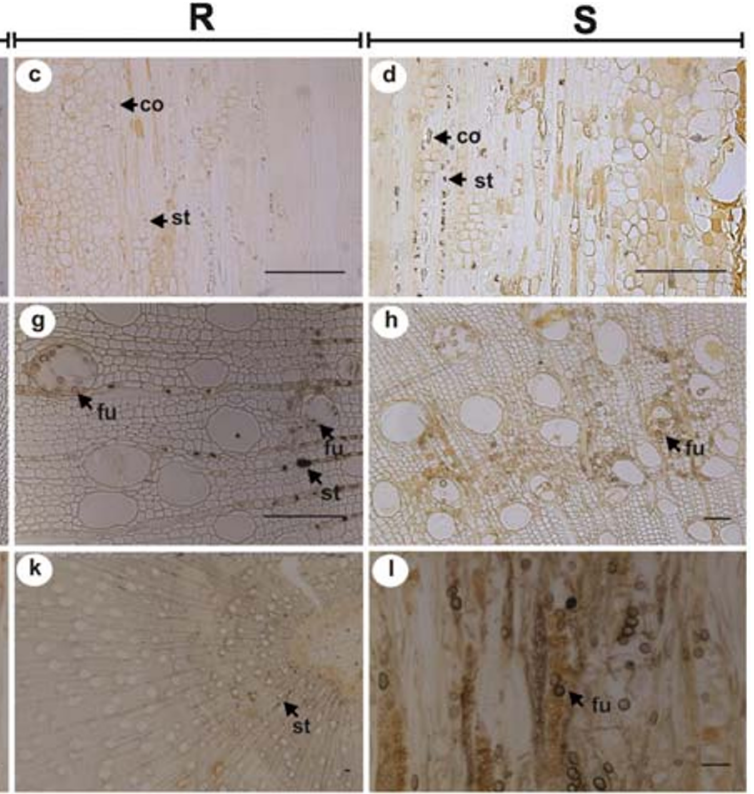

arrows show the deposition of starch in the periderm $(\mathbf{a}-\mathbf{f})$, in the rays $(\mathbf{g}, \mathbf{i}$, and $\mathbf{k})$, and near the fungal colonization site $(\mathbf{g})$ and the deposition of oxalate crystals in the periderm $(\mathbf{a}-\mathbf{f}) . c 0=$ calcium oxalate, $\mathrm{st}=$ starch, and fu $=$ fungus. Scale bars $=100(\mathbf{a}-\mathbf{d}, \mathbf{g}$, and $\mathbf{i})$ and $50 \mu \mathrm{m}(\mathbf{e}, \mathbf{f}, \mathbf{h}$, and $\mathbf{j}-$ l)
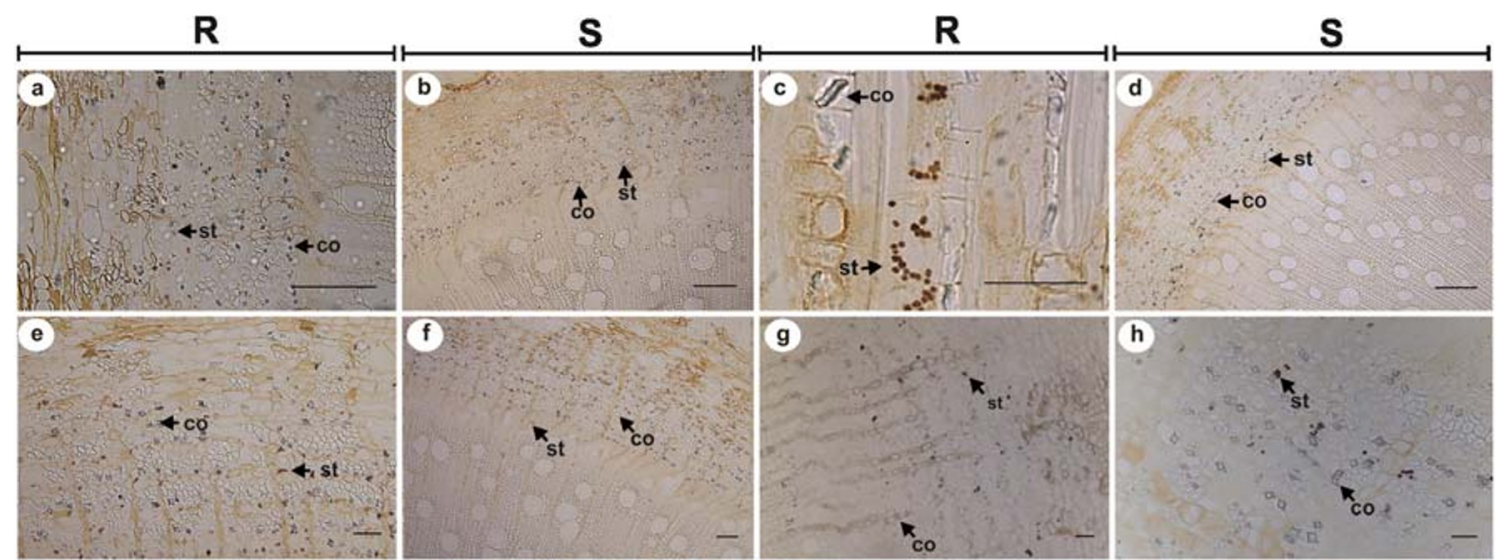
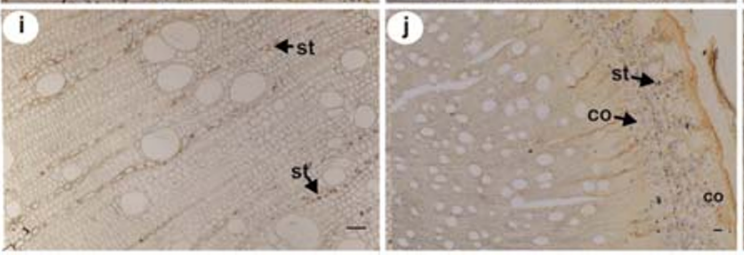

Fig. 13 Histochemical reactions in stem tissue sections of the CLR212 (resistant) (R) and CLR240 (susceptible) (S) clones of Eucalyptus urophylla $\times E$. grandis. The samples were obtained 1 (a and $\mathbf{b}), 2(\mathbf{c}$ and $\mathbf{d}$ ), 4 (e and $\mathbf{f}$ ), 8 (g and $\mathbf{h}$ ), 16 (i and $\mathbf{j}$ ), and 32 ( $\mathbf{k}$ and $\mathbf{l}$ ) days after wounding and stained with lugol. Black arrows show the deposition of

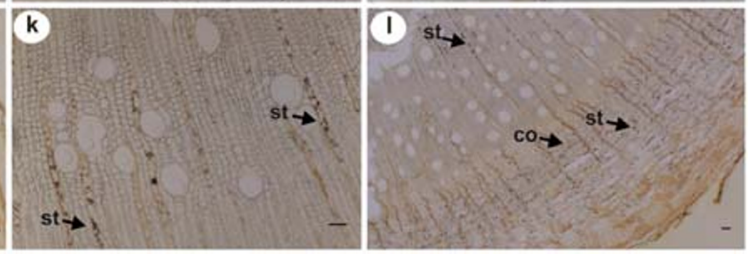

starch in the periderm $(\mathbf{a}-\mathbf{h}, \mathbf{j}$, and $\mathbf{l})$ and in the rays $(\mathbf{i}, \mathbf{k}$, and $\mathbf{l})$ and the deposition of oxalate crystals in the periderm $(\mathbf{a}-\mathbf{h}, \mathbf{j}$, and $\mathbf{l})$. co $=$ calcium oxalate and st $=$ starch. Scale bars $=100(\mathbf{a}, \mathbf{b}$, and $\mathbf{d})$ and $50 \mu \mathrm{m}(\mathbf{c}$ and $\mathbf{e}-$ l) 


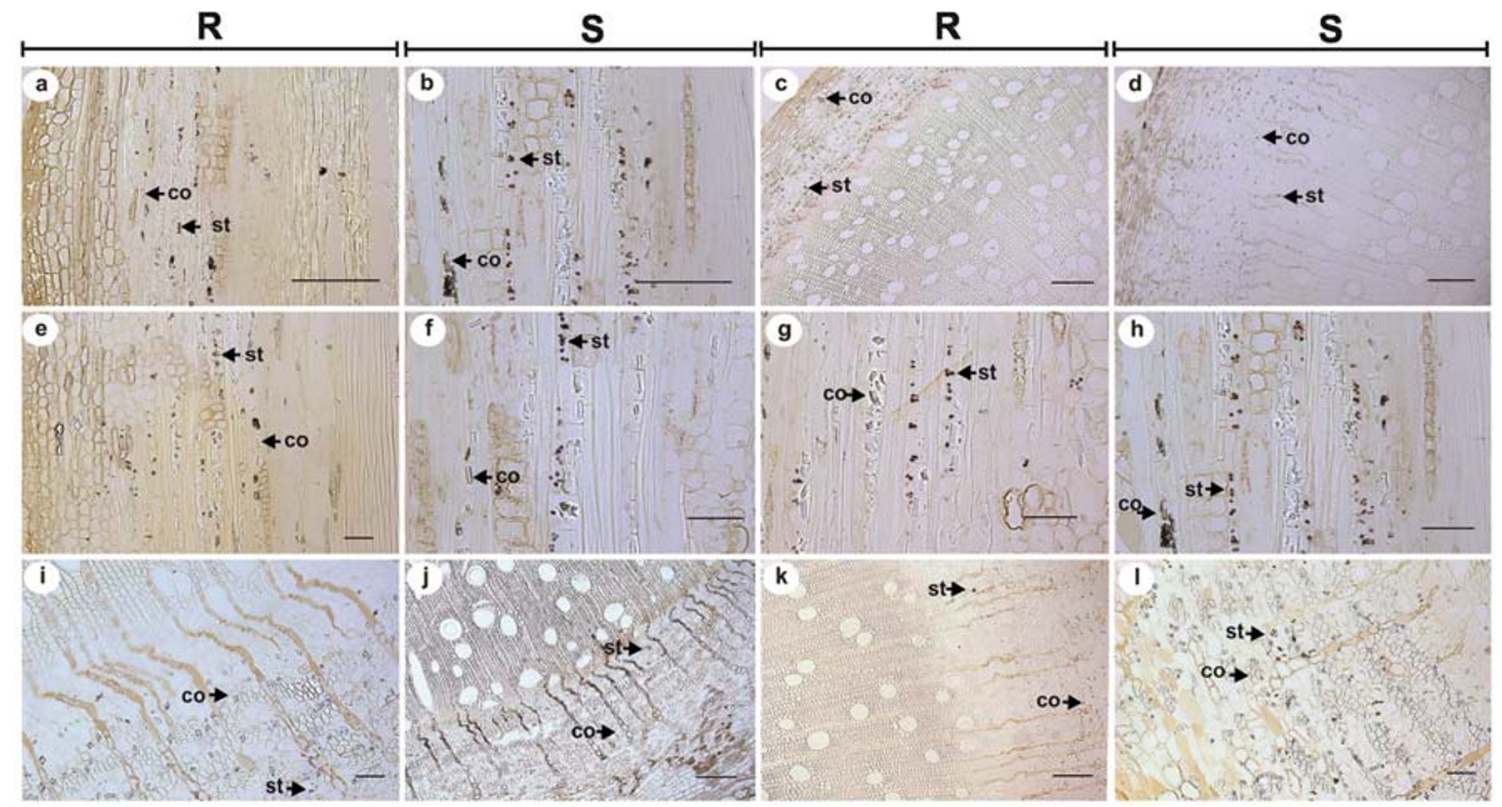

Fig. 14 Histochemical reactions in stem tissue sections of the CLR212 (resistant) (R) and CLR240 (susceptible) (S) clones of Eucalyptus urophylla $\times E$. grandis. The samples were obtained from unwounded and uninoculated plants at 1 (a and b), 2 (c and $\mathbf{d}), 4$ (e and $\mathbf{f}), 8$ (g and h), 16 (i and $\mathbf{j}$ ), and 32 ( $\mathbf{k}$ and $\mathbf{l}$ ) days and stained with lugol. Black arrows

\section{References}

Alfenas AC, Zauza EAV, Mafia RG, Assis TF (2009) Clonagem e doenças do eucalipto, 2 eds. Universidade Federal de ViçosaEditora UFV, Viçosa

Araujo L, Bispo WMS, Cacique IS, Cruz MFA, Rodrigues FA (2014) Histopathological aspects of mango resistance to the infection process of Ceratocystis fimbriata. Plant Pathol 63:1282-1295

Araujo L, Bispo WMS, Rios JA, Fernandes AS, Rodrigues FA (2016) Alkaloids and phenolics biosynthesis increases mango resistance to infection by Ceratocystis fimbriata. Bragantia 75:199-211

Beckman CH (1987) The nature of wilt diseases of plants. APS Press

Chen P, Lee B, Robb J (2004) Tolerance to a non-host isolate of Verticillium dahliae in tomato. Physiol Mol Plant Pathol 64:283291

Clérivet A, El Modafar C (1994) Vascular modifications in Platanus acerifolia seedlings inoculated with Ceratocystis fimbriata $\mathrm{f}$. $\mathrm{sp}$. platani. Eur J Forest Pathol 24:1-10

Clérivet A, Déon V, Alami I, Lopez F, Geiger J-P, Nicole M (2000) Tyloses and gels associated with cellulose accumulation in vessels are responses of plane tree seedlings (Platanus $\times$ acerifolia) to the vascular fungus Ceratocystis fimbriata $\mathrm{f}$. sp platani. Trees 15:25-31

Datnoff LE, Elmer WH, Huber DM (2007) Mineral nutrition and plant disease. The American Phytopathological Society Press, St. Paul

Dixon RA, Paiva NL (1995) Stress-induced phenylpropanoid metabolism. Plant Cell 7:1085-1097

Duncan DR, Himelick EB (1988) Conidial production of Verticillium dahliae as influenced by a negative pressure potential. Can J Bot 66:67-71

Eynck C, Koopmann B, Karlovsky P, Von Tiedemann A (2009) Internal resistance in winter oilseed rape inhibits systemic spread of the vascular pathogen Verticillium longisporum. Phytopathology 99:802811 show the deposition of starch in the periderm $(\mathbf{a}-\mathbf{j})$ and in the rays (k) and the deposition of oxalate crystals in the periderm $(\mathbf{a}-\mathbf{l})$. co $=$ calcium oxalate and st $=$ starch. Scale bars $=100(\mathbf{a}-\mathbf{d}, \mathbf{i}, \mathbf{k}$, and $\mathbf{l})$ and $50 \mu \mathrm{m}$ (e-h and $\mathbf{j})$
Fernandes BV, Zanuncio AJV, Furtado EL, Andrade HB (2014) Damage and loss due to Ceratocystis fimbriata in Eucalyptus wood for charcoal production. Bioresources 9:5473-5479

Ferreira FA, Maffia LA, Barreto RW, Demuner NL, Pigatto S (2006) Sintomatologia da murcha de Ceratocystis fimbriata em eucalipto. Rev Árvore 30:155-162

Firmino AC, Tozze Junior HJ, Furtado EL (2013) Resistência de genótipos de eucalipto a Ceratocystis spp. Sci For 41:165-173

Firmino AC, Tanaka FAO, Silva SDVM, Ito MF, Furtado EL (2015) Colonização do xilema de eucalipto por Ceratocystis spp. isolado de diferentes hospedeiros. Summa Phytopathol 41:138-143

Firmino AC, Tozze Junior HJ, Viana CM, Soliman EP, Gava de Souza IC, Da Silva MR, Tristão LE, Furtado EL (2018) Análise histológica de plantas de eucalipto resistentes e suscetíveis inoculadas com Ceratocystis fimbriata. Sci For 46:209-216

Hall C, Heath R, Guest DI (2011) Rapid and intense accumulation of terpenoid phytoalexins in infected xylem tissues of cotton (Gossypium hirsutum) resistant to Fusarium oxysporum f. sp. vasinfectum. Physiol Mol Plant Pathol 76:182-188

Hammond-Kosack KE, Jones JD (1996) Resistance gene-dependent plant defense responses. Plant Cell 8:1773-1791

Harakava R (2005) Genes encoding enzymes of the lignin biosynthesis pathway in Eucalyptus. Genet Mol Biol 28:601-607

Humphreys JM, Chapple C (2002) Rewriting the lignin roadmap. Curr Opin Plant Biol 5:224-229

Ioannou N, Scheneider RW, Grogan RG (1977) Effect of oxygen, carbon dioxide and ethylene on growth, sporulation and production of microsclerotia by Verticillium dahliae. Phytopathology 67:645-650

Johansen DA (1940) Plant microtechnique. McGraw-Hill, New York

Kpémoua K, Boher B, Nicole M, Calatayud P, Geiger JP (1996) Cytochemistry of defense responses in cassava infected by Xanthomonas campestris pv. manihotis. Can J Microbiol 42:11311143 
Kuroda K (1991) Mechanism of cavitation development in the pine wilt disease. Eur J Forest Pathol 21:82-89

Mafia RG, Ferreira MA, Zauza EAV, Silva JF, Colodette JL, Alfenas AC (2013) Impact of Ceratocystis wilt on eucalyptus tree growth and cellulose pulp yield. For Pathol 43:379-385

Matsuki M (1996) Regulation of plant phenolic synthesis: from biochemistry to ecology and evolution. Aust J Bot 44:613-634

Moller WJ, DeVay JE (1968) Carrot as a species selective isolation medium for Ceratocystis fimbriata. Phytopathology 58:123-124

Niemann GJ, Baayen RP, Boon JJ (1990) Localization of phytoalexin accumulation and determination of changes in lignin and carbohydrate composition in carnation (Dianthus caryophyllus L.) xylem as a consequence of infection with Fusarium oxysporum f. sp. dianthi, by pyrolysis-mass spectrometry. Neth J Plant Pathol 96:133-153

Oliveira LSS, Guimarães LMS, Ferreira MA, Nunes AS, Pimenta LVA, Alfenas AC (2015) Aggressiveness, cultural characteristics and genetic variation of Ceratocystis fimbriata on Eucalyptus spp. For Pathol 45:505-514

Ouellette GB, Rioux D (1992) Anatomical and physiological aspects of resistance to Dutch elm disease. In: Blanchette R, Biggs A (eds) Defense mechanisms of woody plants against fungi. Springer, Berlin, pp 257-307

Park JH, Juzwik J (2014) Ceratocystis smalleyi colonization of bitternut hickory and host responses in the xylem. For Pathol 44:282-292

Pérez-Vera OA, Cárdenas-Soriano E, Alvarado-Rosales D, Cibrián-Tovar D, Equihua-Martínez A (2011) Histopatología del pino de las alturas (Pinus hartwegii Lindl.) inoculado con tres hongos ophiostomatoides. Rev Chapingo Ser Cie 17:91-102

Pimenta L, Ferreira MA, Ribeiro PM Jr, Zacaroni LM, Mafia RG, Resende MLV (2017) Physiological responses of Eucalyptus spp. hybrids to infection by Ceratocystis fimbriata. For Pathol 47:e12336

Pouralibaba HR, Pérez-de-Luque A, Rubiales D (2017) Histopathology of the infection on resistant and susceptible lentil accessions by two contrasting pathotypes of Fusarium oxysporum f. sp. lentis. Eur J Plant Pathol 148:53-63

Rioux D, Nicole M, Simard M, Ouellette GB (1998) Immunocytochemical evidence that secretion of pectin occurs during gel (gum) and tylosis formation in trees. Phytopathology 88: 494-505

Santos RMF, Silva SDVM, Sena K, Micheli F, Gramacho KP (2013) Kinetics and histopathology of the cacao-Ceratocystis cacaofunesta interaction. Trop Plant Biol 6:37-45
Shi J, Mueller WC, Beckman CH (1992) Vessel occlusion and secretory activities of vessel contact cells in resistant or susceptible cotton plants infected with Fusarium oxysporum f. sp. vasinfectum. Physiol Mol Plant Pathol 40:133-147

Silva RR, Silva AC, Rodella RA, Serrão JE, Zanuncio JC, Furtado EL (2017) Pre-infection stages of Austropuccinia psidii in the epidermis of Eucalyptus hybrid leaves with different resistance levels. Forests 8:362. https://doi.org/10.3390/f8100362

Silva AC, De Oliveira Silva FM, Milagre JC, Omena-Garcia RP, Abreu MC, Mafia RG, Nunes-Nesi A, Alfenas AC (2018) Eucalypt plants are physiologically and metabolically affected by infection with Ceratocystis fimbriata. Plant Physiol Biochem 123:170-179

Silva AC, Betancourth BML, Ferreira DC, Elerati TL, Rodrigues FÁ, Alfenas AC (2020) Responses of resistant and susceptible hybrid clones of Eucalyptus urophylla $\times$ Eucalyptus grandis to infection by Ceratocystis fimbriata. V1. Zenodo. [dataset]. https://doi.org/10. 5281/zenodo.3616121

Sun Q, Rost TL, Reid MS, Matthews MA (2007) Ethylene and not embolism is required for wound-induced tylose development in stems of grapevines. Plant Physiol 145:1629-1636

Trang TT, Eyles A, Davies N, Glen M, Ratkowsky D, Mohammed C (2018) Screening for host responses in Acacia to a canker and wilt pathogen, Ceratocystis manginecans. For Pathol 48:e12390

Tumura KG, De Pieri C, Furtado EL (2012) Murcha por Ceratocystis em eucalipto: avaliação de resistência e análise epidemiológica. Summa Phytopathol 38:54-60

Tuncel G, Nergiz C (1993) Antimicrobial effect of some olive phenols in a laboratory medium. Lett Appl Microbiol 17:300-302

Vance CP, Kirk TK, Sherwood RT (1980) Lignification as a mechanism of disease resistance. Annu Rev Phytopathol 18:259-288

Viiri H, Niemelä P, Kitunen V, Annila E (2001) Soluble carbohydrates, radial growth and vigour of fertilized Norway spruce after inoculation with blue-stain fungus, Ceratocystis polonica. Trees 15:327334

Whetten R, Sederoff R (2004) Lignin biosynthesis. Plant Cell 7:10011013

Zauza EAV, Alfenas AC, Harrington TC, Mizubuti ES, Silva JF (2004) Resistance of Eucalyptus clones to Ceratocystis fimbriata. Plant Dis $88: 758-760$

Publisher's note Springer Nature remains neutral with regard to jurisdictional claims in published maps and institutional affiliations.

\section{Affiliations}

\section{André C. Silva ${ }^{1,2} \cdot$ Blanca M. L. Betancourth ${ }^{3}$. Diego C. Ferreira ${ }^{4} \cdot$ Tamiris L. Elerati $^{5} \cdot$ Fabrício Á. Rodrigues $^{1}$. Acelino C. Alfenas ${ }^{1}$}

1 Departamento de Fitopatologia, Universidade Federal de Viçosa, Viçosa, MG 36570-900, Brazil

2 Departamento de Fitossanidade, Universidade Federal do Rio Grande do Sul, Porto Alegre, RS 91540-000, Brazil

3 Departamento de Biologia Geral, Programa de Pós-graduação em Genética e Melhoramento, Universidade Federal de Viçosa, Viçosa, MG 36570-900, Brazil
4 Departamento de Engenharia Florestal, Programa de Pós-graduação em Ciência Florestal, Universidade Federal de Viçosa, Viçosa, MG 36570-900, Brazil

5 Departamento de Biologia Vegetal, Universidade Federal de Viçosa, Viçosa, MG 36570-900, Brazil 